Article

\title{
Analysis of Scale Factors on China's Sustainable Development Efficiency Based on Three-Stage DEA and a Double Threshold Test
}

\author{
Jianqing Zhang ${ }^{1,2}$, Song Wang ${ }^{1,3}$, Peilei Yang ${ }^{4}$, Fei Fan ${ }^{1,3, * \mathbb{C}}$ and Xueli Wang ${ }^{1, *}$ \\ 1 Institute for the Development of Central China, Wuhan University, Wuhan 430072, China; \\ jqzhang@whu.edu.cn (J.Z.); 2017106320003@whu.edu.cn (S.W.) \\ 2 School of economics and management, Wuhan University, Wuhan 430072, China \\ 3 School of Earth and Environmental Sciences, University of Queensland, Brisbane 4072, Australia \\ 4 School of urban and Regional Sciences, Shanghai University of Finance and Economics, Shanghai 200083, \\ China; yangpl@mail.shufe.edu.cn \\ * Correspondence: ffan@whu.edu.cn (F.F.); sherrywang@whu.edu.cn (X.W.)
}

Received: 30 January 2020; Accepted: 11 March 2020; Published: 12 March 2020

\begin{abstract}
Based on the Driver-Pressure-State-Impact-Response (DPSIR) framework, this paper constructs the input, expected output, and unexpected output of China's sustainable development. This paper calculates the sustainable development efficiency of 31 provinces and cities in China using a super-slack-based measure (SBM) model that eliminates the influence of scale factors through a three-stage data envelope analysis (DEA) approach. Taking the level of science and technology as the control variable, and the relative scale efficiency as the threshold variable, this paper calculates the effects of the absolute scale of labor force, education, economy, enterprise, and transportation on sustainable development efficiency. The results show that: (1) there is an upward trajectory for sustainable development efficiency of China's provinces and municipalities overall from 0.65 in 2004 to 0.68 in 2017, with significant regional differences in which the ecological efficiency in the Eastern region is 0.26 higher than that of the Central region; (2) it enhances the absolute scale of the labor force, education, and transportation, in order to reduce the inhibition on sustainable development efficiency; and (3) shifts our attention to the promotion of absolute economic scale to the promotion of green economic development, and increases control of polluting enterprises.
\end{abstract}

Keywords: sustainable development efficiency; three stage; influence of scale; threshold test

\section{Introduction}

In the 200 years since the Industrial Revolution, the unprecedented speed and scale of population growth has changed the Earth's life support system. On the one hand, science and technology are developing rapidly, with growth in the scale and sophistication of human society, and the agglomeration of economies. On the other hand, human society is facing arduous challenges because of rapid global population growth, the shortage of natural resources, and the deterioration of the ecological environment. In response to that, the United Nations convened the Conference on Environment and Development in Rio de Janeiro, Brazil, in 1992. The conference introduced important documents such as the Rio Declaration on Environment and Development [1], which reflected the common aspiration of all countries in the world to work together to protect the human environment, and Agenda 21 [2] which provided a global framework for taking steps to safeguard our common future and rapidly popularize the concept of sustainable development worldwide [3]. Since then, a large number of related studies have been published on the subject and its related fields. Within the growing research community, sustainable development has been elevated from regional to national and international focus. Research 
focus on sustainable development has expanded from evaluation and measurements of efficiency to a comprehensive investigation into social, economic, and ecological impacts, influenced by variables including science, technology, and scale. Therefore, it is important to establish a framework that includes economic, social, and ecological impacts from sustainable development efficiency concerns and analyze the impact of technology and scale.

In the past forty years since China's social and economic reforms and opening-up, the economy has rapidly developed into what is now the second largest economy in the world. However, problems concerning ecological systems and biodiversity as well as environmental issues cannot be ignored [4]. The Chinese government has begun to pay attention to sustainable development and has made a series of efforts in that regard [5]. In 1994, the Chinese government compiled "China's Agenda 21: China's White Paper on Population, Environment and Development in the 21st Century," which integrates sustainable development into the long-term planning of China's economy and society for the first time. In 1997, the 15th National Congress of the Communist Party of China adopted sustainable development as a strategic goal of China's development and emphasized it in subsequent sessions of the National Congress of the Communist Party of China. The emphasis on sustainable development in China has been increasing in recent years. However, due to China's economic slowdown, resource constraints, and other factors, ecological deterioration among other issues have seriously affected the rate of economic and social development [6]. Therefore, China must shift its emphasis from a rapid rate of economic development to enhancing sustainable development efficiency.

The key to improving efficiency is to analyze the mechanisms of different factors influencing efficiency, and to take measures in an orderly manner according to these influences. However, there are some deficiencies in the existing research on the influence mechanisms of sustainable development efficiency: (i) Scale and innovation are the most important factors affecting economic development, and they also affect the efficiency of sustainable development. Most of the existing studies focus on the impact of innovation but ignore the scale factor. (ii) Many indicators are involved in the efficiency of sustainable development, and the input indicators of efficiency may be part of the influencing factors, which can lead to the influencing factors being taken into account in the calculation of efficiency. When analyzing the mechanism of influencing factors, these influencing factors are not eliminated, resulting in a deviation of analysis. (iii) After the influencing factors reach a specific value, their effects on the efficiency of sustainable development may be different. If the change of influence coefficient is not considered, the same policy under the fixed coefficient may lead to wasted resources.

Based on the analysis of these three situations that may occur relative to influencing factors, this paper takes the scale factor as the core explanatory variable, and innovation as the control variable, mainly to explore the impact of the scale factor on the efficiency of sustainable development, making up for (i). This paper first eliminates the effect of influencing factors on the efficiency of sustainable development through the three-stage data envelope analysis (DEA) model, and then analyzes the mechanism of these influencing factors on sustainable development to avoid the possible calculation errors caused by (ii). In the analysis of influencing factors, this paper uses a panel threshold regression model to explore the effect of influencing factors on the efficiency of sustainable development under different circumstances, and then makes corresponding policy suggestions according to the different effect coefficients, thus avoiding the possible waste of resources caused by (iii).

\section{Literature Review}

\subsection{Sustainable Development Research}

The United Nations Declaration of the Human Environment in Stockholm, Sweden, 1972; the Rio Declaration in Rio de Janeiro, Brazil, 1992; the Johannesburg Declaration on Sustainable Development in Johannesburg, South Africa, 2002; and The Future We Want in Rio de Janeiro, Brazil, in 2012 all advanced the idea of sustainable development [7]. Sustainable development has become a frontier research field for many disciplines. Regional sustainable development involves multiple dimensions 
such as geographical distribution, availability of natural resources and the environment, and social economic systems and human activities, and it is gradually becoming the main research direction of sustainable development at this stage [8]. Most studies on sustainable development focus on the level evaluation of sustainable development. Using nonlinear principal component analysis and Gram-Schmidt orthogonalization, Tan and Lu evaluated the sustainable development of the provinces and cities around the Bohai Sea in China [9] and Orenstein and Pinsley presented a framework that evaluated the merits and drawbacks of sustainable development initiatives [10]. Using a Geographic Information System (GIS) and System Dynamics (SD) model to measure the sustainable development of the Ha-Da-Qi industrial corridor, Wan et al. found that predatory exploitation of resources was the main factor contributing to ecological deterioration [11]. Through the comprehensive weighting of indicators, Carrillo and Jorge measured the sustainability of regional tourism in Spain. Based on Strengths-Weaknesses-Opportunities-Threats (SWOT) analysis [12], Arbolino et al. assessed the sustainability of Italy's regional industry [13]. Chelan et al. provided policy makers with a clear analysis of available resources and opportunities by assessing sustainable development in the shaman summer pastoral area [14]. Using data from 31 provinces and municipalities in China, Su and An found that the level of regional innovation had a significant double threshold effect on sustainable development [15]. Improving the level of sustainable development is a difficult process, requiring a shift in attention to improve the efficiency of sustainable development in regions hindered by resource limitations [16].

\subsection{Sustainable Development Efficiency}

Efficiency as a macroeconomic concept defines the ratio of effective output to actual input across a defined period, which is directly proportional to output and inversely proportional to input [17]. Accordingly, some researchers give the definition of sustainable development efficiency according to different research objectives. Wanke believes the sustainable development efficiency of a transportation system is a comprehensive assessment considering different modes of transportation, technical characteristics, energy consumption, and carbon dioxide emissions [18]. Yan gives the definition of sustainable development efficiency for an urban system, and states that urban sustainable development efficiency is the comprehensive efficiency that includes natural resources, the ecosystem, plus the environment and human welfare [19]. Although there are few studies on sustainable development efficiency, and the definition of sustainable development efficiency is based on a specific system, these definitions all contain two core ideas, which should involve as many indicators of the studied system as possible and take into account ecological environmental factors. Therefore, combined with sustainable development thought and the concepts of economic efficiency, financial efficiency, energy efficiency, ecological efficiency, and environmental efficiency, sustainable development efficiency in this paper refers to the ratio between the comprehensive benefits obtained and the cost of production factors invested on the basis of ensuring the stable and healthy operation and rapid development of the whole economy and society, through the effective utilization of resources and the improvement of production performance to reduce the ecological consumption. In recent years, with in-depth studies and extensive uses of a DEA model, a significant number of research results have emerged that focus on the efficiency of macro-economic operations and micro-enterprise developments. The macro-economic operation efficiency mainly involves research at national [20,21] and regional [22] levels, and the research of enterprise efficiency mainly focuses on the research of banks [23] and other enterprises. According to different assessments, efficiency research may also involve ecological efficiency [24], traffic efficiency [25], and technological innovation efficiency [26,27].

With DEA incorporating unexpected outputs into the model, studies on ecological efficiency have also been initiated. Madaleno et al. measured the ecological efficiency of 26 European Union (EU) member states and found that different input-output models could lead to changes in the rankings of countries' ecological efficiency [28]. Moutinho et al. measured the ecological efficiency of $26 \mathrm{EU}$ countries and analyzed the influencing factors of ecological benefits [29]. Xing et al. combined 
economic input-output life cycle assessments using DEA on the environmental impact and ecological efficiency of different economic sectors in China [30]. Song et al. calculated the ecological efficiency of different regions in China and found that the ecological efficiency of China differs significantly based on the region [31]. Economic and ecological efficiency alone cannot reflect the overall effectiveness of economic and social operations. Economy, society, energy, and ecology must be analyzed within a consistent framework for sustainable development to reflect the overall operations and efficiency of the economy and society. Deilmann et al. used a nine-field matrix to analyze the characteristics and differences between economic efficiency and ecological efficiency in 116 German cities [32]. Suzuki and Nijkamp used the improved DEA model to measure energy-eco-economic efficiency in the EU, Asia Pacific Economic Cooperation (APEC), and Association of South-East Asian Nations (ASEAN) regions and found the EU to be the most efficient [33]. Sun et al. used the network DEA model to measure the efficiency of marine composite systems in coastal provinces and cities of China [34]. By integrating ecological efficiency and other related efficiencies, including economic efficiency, energy efficiency, and environmental efficiency in a unified framework, Huang et al. calculated and analyzed integrated ecological efficiency [35]. Equivalent to the sustainable development efficiency, these studies on ecological efficiency cover less content and cannot fully reflect all aspects of sustainable development. However, these studies give us great inspiration in the selection of indicators and the use of methods on the calculation of sustainable development efficiency.

\subsection{Influencing Factors of Sustainable Development Efficiency}

Limitations exist whereby sustainable development efficiency can only represent the efficiency of existing sustainable development in countries and cannot guide the construction of sustainable development. Therefore, it is necessary to explore the influencing factors of sustainable development efficiency to identify key variables and factors for improving sustainable development efficiency. There are few studies on sustainable development efficiency; however, studies on the influencing factors of economic growth, economic efficiency, ecological efficiency, and energy efficiency indicate the impact of different factors on sustainable development efficiency, which can still have significance for studies on influencing factors for sustainable development efficiency. Francois Perroux (1903-1987) emphasized that technological progress and innovation are the core driving forces of economic growth [36]. Thus, the related research on the influencing factors of economic efficiency is mostly centered on technological innovation. Tzeremes found that human capital accumulation promoted national economic efficiency growth through increased technological prowess [37]. Aparicio et al. discussed economic efficiency under the heterogeneous technology level by using alternative allocation and technical efficiency standards [38]. When inspecting the influence of human capital on national economic efficiency, Wang et al. found productivity showed opposite changes to carbon dioxide emissions, and the overall efficiency of APEC members showed an upward trend from 2001 to 2010, mainly due to technological progress [39]. Sebastián and Laura believe that technological superiority implies economic superiority, but the reverse is not true because economic superiority has a deeper structure [40]. In a study of electric power distribution companies in Brazil, Zorzo et al. found a low correlation between technological innovation and economic efficiency, mainly due to the fact that technological innovation is in its infancy [41]. Habyarimana and Opoku found that China's technology transfer and foreign direct investment in Africa would lead to technological stagnation and economic growth in Africa [42]. Yang and Zhang found that technological progress is the decisive factor in China's regional ecological efficiency [43].

System integration is a necessity for sustainable development [44]. Apart from technology, scale is also an important factor in determining efficiency. Chiu et al. analyzed transit efficiency and found that the large-scale transit development in China's coastal areas does not represent greater transit efficiency [45]. In an analysis of China's energy, environmental, and economic efficiency, Wang and Feng found that the decline in scale was one of the main obstacles to efficiency [46]. In a study of the influencing factors on the land use efficiency of economic development zones in Shanghai, Huang et al. 
found that selection and agglomeration have positive effects on improving land use efficiency [47]. When measuring the ecological efficiency of the Yangtze River Economic Belt, Huang et al. found that the ecological efficiency of urban agglomerations was higher than that of non-urban agglomerations, and the cities with high ecological efficiency were increasingly agglomerating [48]. Han et al. examined the relationship between industrial organization levels, natural resource endowment, and eco-economic efficiency in China in the past decade and concluded that the industrial organization level was positively correlated with eco-economic efficiency while natural resource endowment was negatively correlated with eco-economic efficiency [49]. Based on the experience of urban efficiency development in Germany, Deilmann et al. believe that agglomeration is not the only factor determining efficiency, and high density does not produce efficiency [50]. There are also studies on the impact of energy on efficiency. By calculating the influencing factors of energy efficiency in China's economic system, Bian et al. found that economic development has a positive effect on energy efficiency while energy structure adjustment has a negative effect on energy efficiency [51]. Rajbhandari and Zhang found that there is a strong correlation between energy input and economic growth in middle- and high-income countries and economies [52]. Vaninsky believes that economic restructuring can enhance global energy efficiency [53].

In summary, there is extensive relevant research on sustainable development; however, it mainly focuses on the evaluation of regional sustainable development. There are few studies on the evaluation of sustainable development efficiency, and the research related to sustainable development efficiency focuses on the single aspect of economic efficiency or ecological efficiency. In addition, the research on influencing factors mainly focuses on two aspects, science and technology and scale. Therefore, this paper uses a Driver-Pressure-State-Impact-Response (DPSIR)-DEA model to measure sustainable development efficiency in China. Taking the level of science and technology as the control variables and using a threshold regression model, the impact of different scale levels of influencing factors on sustainable development efficiency is measured.

\section{Method}

\subsection{DPSIR-DEA Model}

DEA is a nonparametric method commonly used to measure relative efficiency by analyzing multiple input and output factors proposed by Charnes et al. [54]. The sum of the number of input-output indicators for decision-making units in a DEA model is generally the number of Decision Making Units (DMU) 1/3. A sum of the number of the input-output indicators that is too large or too small will result in inaccurate results. However, the evaluation of sustainable development calls for comprehensive indicators. An increase in the number of indicators will result in an inaccurate calculation for final efficiency and, ultimately, affect the formulation of relevant policies. The combination of the DPSIR framework and the DEA model can cover the relevant indexes more comprehensively and accurately calculate sustainable development efficiency to solve the aforementioned problems [55].

\section{DPSIR Framework}

The DPSIR model is established by taking the advantages of the Pressure-State-Response (PSR) and Driving Force-State-Response (DSR) frameworks of the European Environment Agency (EEA). These frameworks are used to describe and solve the environmental management model of the causality between the economic and environmental system departments. The DPSIR model divides the evaluation index of a system into five types of DPSIRs and, according to the requirements of different evaluation systems, each type is divided into several indexes. As the DPSIR model has the advantages of being comprehensive and logical, it is increasingly applied to the evaluation of sustainable development.

We basically use the research indicators of Zhang et al. [16] and Wang et al. [55] to establish the DPSIR framework, as Table 1 shows, and the reasons for the selection of indicators and the corresponding 
references can also be found in their research. According to the calculations by Zhang et al. [16] and Wang et al. [55] of China's sustainable development efficiency, using the DPSIR-DEA model, driving force, resource consumption in pressure, and response are inputs of the DEA model, while state and impact are the desirable outputs. Ecological damage in pressure, which represents the malignant impact of economic development on ecology, is the undesirable output.

Table 1. The Driver-Pressure-State-Impact-Response (DPSIR) framework for China's sustainable development.

\begin{tabular}{|c|c|c|c|c|c|}
\hline \multirow{2}{*}{ Variables } & \multirow{2}{*}{$\begin{array}{l}\text { Indicators Indicating the } \\
\text { Content of Variables }\end{array}$} & \multirow{2}{*}{$\begin{array}{l}\text { Unit of } \\
\text { Indicators }\end{array}$} & \multicolumn{3}{|c|}{ Weights of Indicators } \\
\hline & & & $\begin{array}{l}\text { Subjective } \\
\text { Weight }\end{array}$ & $\begin{array}{l}\text { Objective } \\
\text { Weight }\end{array}$ & $\begin{array}{c}\text { Comprehensive } \\
\text { Weight }\end{array}$ \\
\hline \multirow{3}{*}{ Driving force } & Natural population growth rate & $\%$ & 0.25 & 0.13 & 0.08 \\
\hline & Population density & $\begin{array}{l}\text { persons } / 10^{6} \\
\mathrm{hm}^{2}\end{array}$ & 0.48 & 0.67 & 0.78 \\
\hline & Urbanization & $\%$ & 0.27 & 0.20 & 0.13 \\
\hline \multirow{3}{*}{$\begin{array}{l}\text { Resource } \\
\text { consumption }\end{array}$} & Investment in energy industry & $10^{8}$ yuan & 0.28 & 0.27 & 0.22 \\
\hline & $\begin{array}{l}\text { Power consumption of } 10,000 \\
\text { yuan gross domestic product } \\
\text { (GDP) }\end{array}$ & $10^{8} \mathrm{~kW} \cdot \mathrm{h}$ & 0.36 & 0.29 & 0.31 \\
\hline & $\begin{array}{l}\text { Water consumption of } 10,000 \\
\text { yuan GDP }\end{array}$ & $\mathrm{m}^{3}$ & 0.36 & 0.44 & 0.47 \\
\hline \multirow{3}{*}{$\begin{array}{l}\text { Ecological } \\
\text { damage }\end{array}$} & Waste ater discharge & $10^{4} \mathrm{t}$ & 0.33 & 0.39 & 0.38 \\
\hline & Exhaust emissions & $10^{8} \mathrm{~m}^{3}$ & 0.31 & 0.28 & 0.26 \\
\hline & Waste solid discharge & $10^{4} \mathrm{t}$ & 0.36 & 0.33 & 0.36 \\
\hline \multirow{4}{*}{ State } & $\begin{array}{c}\text { The proportion of the tertiary } \\
\text { industry }\end{array}$ & $\%$ & 0.1 & 0.23 & 0.09 \\
\hline & $\begin{array}{l}\text { The contribution rate of the } \\
\text { tertiary industry }\end{array}$ & $\%$ & 0.32 & 0.31 & 0.37 \\
\hline & $\begin{array}{l}\text { Comparative labor } \\
\text { productivity }\end{array}$ & - & 0.21 & 0.16 & 0.12 \\
\hline & Urban green area per capita & $\mathrm{m}^{2}$ & 0.37 & 0.30 & 0.42 \\
\hline \multirow{3}{*}{ Impact } & Per capita GDP & $10^{4}$ yuan & 0.36 & 0.47 & 0.47 \\
\hline & GDP growth rate & $\%$ & 0.25 & 0.16 & 0.11 \\
\hline & Per capita fixed assets stock & $10^{4}$ yuan & 0.39 & 0.38 & 0.42 \\
\hline \multirow{6}{*}{ Response } & $\begin{array}{l}\text { Industrial structure change } \\
\text { index }\end{array}$ & - & 0.25 & 0.19 & 0.29 \\
\hline & $\begin{array}{l}\text { Standard rate of discharge of } \\
\text { industrial wastewater }\end{array}$ & $\%$ & 0.16 & 0.12 & 0.11 \\
\hline & Forest coverage & $\%$ & 0.16 & 0.11 & 0.11 \\
\hline & $\begin{array}{l}\text { The proportion of employees in } \\
\text { the environment }\end{array}$ & $\%$ & 0.14 & 0.16 & 0.14 \\
\hline & $\begin{array}{c}\text { Environmental investment } \\
\text { accounts for the proportion of } \\
\text { GDP }\end{array}$ & $\%$ & 0.13 & 0.18 & 0.14 \\
\hline & $\begin{array}{l}\text { Per capita educational } \\
\text { expenditure }\end{array}$ & $\%$ & 0.16 & 0.23 & 0.22 \\
\hline
\end{tabular}

The index in Table 1 shows different weights allocated to each indicator and their importance to sustainable development overall. This paper used a method that combines subjective and objective weights. Subjective weight is allocated using the analytic hierarchy process (AHP). The subjective weight mainly refers to the research results of Zhang et al. using the Yaahp software [16]. The results are shown in the fourth column of Table 1. The objective weight is determined according to the entropy method. The concrete method refers to the research results of Wang et al. [27], and the results are shown in the fifth column of Table 1. Comprehensive weights are determined according to the Dempster-Shafer (D-S), theory evidence synthesis method to avoid simple average divergence between subjective and objective weights. Specific methods refer to the research results of Zhang et al. [56], and 
the results are shown in the sixth column of Table 1. Taking the sum of the product of the comprehensive weight and data by index standardization, the evaluation values for all first level indicators were obtained then integrated into the DEA framework.

\subsection{Three Stage Super-Slack-Based Measure Model}

\subsubsection{Stage 1: Super-Slack-Based Measure Model}

The classical DEA method does not consider the influence of relaxation quantity, which may cause errors in the efficiency measure. The classical DEA method also does not consider the possible influence of the external environment and the random error of each subject. In addition, the efficiency score may contain deviations from the actual efficiency level [57]. By introducing input and output slack in the target function, Tone [58] and Fukuyama and Weber [59] proposed a non-radial, non-angle-based efficiency evaluation model, known as slack-based measure (SBM). This method simultaneously solves the problem of non-zero relaxation between input and output and the problem of undesired output in the production process [60]. However, this method cannot solve the problem of the inability to distinguish the efficiency of the effective decision unit. Therefore, based on SBM, Tone suggested a super-SBM efficiency model [61] with the following mathematical expression:

$$
\begin{aligned}
& \rho^{*}=\min \rho=\min \frac{1-\left(\frac{1}{N} \sum_{n=1}^{N} \frac{s_{n}^{x}}{x_{n}^{k^{\prime}}}\right)}{1+\left[\frac{1}{M+1}\left(\sum_{m=1}^{M} \frac{s_{m}^{y}}{y_{m}^{k^{\prime}}}\right)+\sum_{i=1}^{I} \frac{s_{i}^{b}}{b_{i}^{k^{\prime}}}\right]} \\
& \text { s.t. } \sum_{k=1}^{K} z_{k}^{b} b_{i}^{k}+s_{i}^{b}=b_{i}^{k^{\prime}}, i=1, \cdots, I ; \\
& \sum_{k=1}^{K} z_{k}^{x} x_{n}^{k}+s_{n}^{x}=x_{n}^{k^{\prime}}, n=1, \cdots, N ; \\
& z_{k}^{i} \geq 0, s_{m}^{y} \geq 0, s_{i}^{b} \geq 0, s_{n}^{x} \geq 0, k=1, \cdots K .
\end{aligned}
$$

In Equations (1) and (2), $\rho$ is the sustainable development efficiency value to be calculated, while $N, M$, and $I$ are the number of inputs, desirable outputs, and undesired outputs, respectively. $\left(s_{m}^{y}, s_{i}^{b}, s_{n}^{x}\right)$ represents the slack variable of input and output. $\left(y_{m}^{k}, b_{i}^{k}, x_{n}^{k}\right)$ is the input and output value of the $\mathrm{k}^{\prime}$ production unit in the $\mathrm{t}^{\prime}$ period, and $\left(z_{k}^{y}, z_{k}^{x}\right)$ represents the weight of input and output. The objective function $\rho$ is strictly monotonically decreasing of $s_{m}^{y}, s_{i}^{b}, s_{n}^{x}$ while $0<\rho \leq 1$. When $\rho \geq 1$, the production unit is fully effective. When $\rho<1$, there is a loss of efficiency in the production unit, which can be improved by optimizing input volume, desirable output, and undesired output. When $b_{i}^{k}, s_{i}^{b}$ are deleted, Equation (2) becomes a general SBM model without considering the undesirable outputs.

\subsubsection{Stage 2 and 3: Stochastic Frontier Approach and Adjusted DEA Model}

Fried believes that the efficiency values calculated by traditional DEA analysis are inaccurate because the effects of environmental factors, random factors, and management efficiency are not eliminated [62]. The SBM value calculated based on the DEA method only separates the undesirable outputs, and other factors that affect sustainable development efficiency remain. Sustainable development efficiency is influenced by science and technology, as well as economy of scale. Thus, in the second stage, the other environment and random factors that affect sustainable development efficiency are separated by establishing a stochastic frontier approach model to obtain the true input value under the same scale. Stochastic frontier approach model obtains production frontier and random hypothesis by comparing the distance between actual output and maximum output under the condition of equal input of each production unit and estimates technical efficiency with technical 
ineffectiveness error. Compared with DEA, the main advantage of the stochastic frontier approach is to consider the random error caused by measurement error and other factors, so as to avoid the improper inclusion of these random error components into the efficiency term. Specifically, labor force scale, education scale, economic scale, enterprise scale, traffic scale, and other factors in the inefficiency function are now included. The equation can be expressed as follows:

$$
S_{n i}=f\left(Z_{i} ; \beta_{n}\right)+v_{n i}+\mu_{n i} ; i=1,2, \cdots, I ; n=1,2, \cdots, N
$$

In Equation (3), $S_{n i}$ is the relaxation value for item $n$ of the $i$ decision unit while $Z_{i}$ is the environment variable. $\beta_{n}$ is the coefficient of the environment variable, $v_{n i}+\mu_{n i}$ is a mixed error term, $v_{n i}$ refers to random interference, and $\mu_{n i}$ represents inefficiency management. Among them, $v \sim N\left(0, \sigma_{v}^{2}\right)$ is a random error term indicating the influence of random interference factors on input relaxation variables. $\mu$ is the management inefficiency, which indicates the influence of management factors on input slack variables. In this paper, $\mu$ is assumed to obey the normal distribution at zero point truncation; that is, $\mu \sim N^{+}\left(0, \sigma_{\mu}^{2}\right)$.

The purpose of stochastic frontier approach regression is to eliminate the influence of environmental factors and random factors on efficiency measurement to adjust all decision units in the same external environment. The adjustment equation is as follows:

$$
X_{n i}^{A}=X_{n i}+\left[\max \left(f\left(Z_{i} ; \hat{\beta}_{n}\right)\right)-f\left(Z_{i} ; \hat{\beta}_{n}\right)\right]+\left[\max \left(v_{n i}\right)-v_{n i}\right] i=1,2, \cdots, I ; n=1,2, \cdots, N
$$

In Equation (4), $X_{n i}^{A}$ is the adjusted input, and $X_{n i}$ is the input before the adjustment. $\left[\max \left(f\left(Z_{i} ; \hat{\beta}_{n}\right)\right)-f\left(Z_{i} ; \hat{\beta}_{n}\right)\right]$ is the adjustment of the external economic environment factors and $\left[\max \left(v_{n i}\right)-v_{n i}\right]$ is the adjustment to give all decision-making units in the same exterior condition.

Using the adjusted input $X_{n i}^{A}$ from stage 2, the revised value of super-SBM is calculated. This eliminates the effect of the undesired output, separates the environmental variables of the economic scale from the efficiency, and obtains the sustainable development efficiency without the influence of the absolute scale effect.

\subsection{Threshold Regression Model}

The threshold regression model is proposed by Hansen [63]. The basic idea is that when a certain explanatory variable is in different intervals, the effect on the explanatory variables is significantly different. The single threshold regression model is as follows:

$$
Y_{i t}=\alpha X_{i t}+\beta_{1} T_{i t} \times I\left(T_{i t} \leq \delta_{1}\right)+\beta_{2} T_{i t} \times I\left(T_{i t}>\delta_{1}\right)+C+\varepsilon_{i t}
$$

In Equation (5), $Y$ is the explanatory variable of $t$ in area $i . X$ is the control variable, and $T$ is the threshold variable. $\delta$ is a fixed threshold, and $\alpha$ is the influence coefficient of $X_{i t}$ on the explanatory variables. $\beta_{1}$ and $\beta_{2}$ are the influence coefficients on the interpreted variable of the threshold variable $T_{\mathrm{it}}$, when $T_{i t} \leq \delta_{1}$ and $T_{\mathrm{it}}>\delta_{1}$, respectively. $C$ is a constant term. $\varepsilon_{i t} \sim\left(0, \sigma^{2}\right)$ is a random perturbation term, and $I(\cdot)$ is an indicator function. Similarly, the double threshold test and the triple threshold test equations are as follows.

$$
\begin{gathered}
Y_{i t}=\alpha X_{i t}+\beta_{1} T_{i t} \times I\left(T_{i t} \leq \delta_{1}\right)+\beta_{2} T_{i t} \times I\left(\delta_{1}<T_{i t} \leq \delta_{2}\right)+\beta_{3} T_{i t} \times I\left(\delta_{2}<T_{i t} \leq \delta_{3}\right)+C+\varepsilon_{i t} \\
Y_{i t}=\alpha X_{i t}+\beta_{1} T_{i t} \times I\left(T_{i t} \leq \delta_{1}\right)+\beta_{2} T_{i t} \times I\left(\delta_{1}<T_{i t} \leq \delta_{2}\right)+\beta_{3} T_{i t} \times I\left(\delta_{2}<T_{i t} \leq \delta_{3}\right)+\beta_{4} T_{i t} \times I\left(\delta_{3}<T_{i t} \leq \delta_{4}\right)+C+\varepsilon_{i t}
\end{gathered}
$$

In Equations (6) and (7), the significance of $\beta_{3}$ and $\beta_{4}$ is similar to that of $\beta_{1}$ and $\beta_{2}$, which are the influence coefficients on the interpreted variable of the threshold variable $T_{\mathrm{it}} . \delta_{2}, \delta_{3}$, and $\delta_{4}$ are the second, third, and fourth fixed thresholds, respectively. Other indicators have the same meaning as in Equation (5). 
Comprehensive sustainable development efficiency is calculated using the first stage super-SBM model as the explanatory variable through the constant returns to scale (CRS) calculation. The relative scale efficiency (RSE; the ratio of the comprehensive efficiency of the CRS calculation with the technical efficiency of the variable returns to scale (VRS)) of the third stage of sustainable development efficiency after the elimination of the absolute scale is the explanatory variable. The threshold variables of absolute scale are labor force scale, education scale, economic scale, enterprise scale, and traffic scale. The control variables are the human resources of science and technology (including the number of people in science and technology, the number of Internet users, the full-time equivalent of R\&D personnel), the market environment (including the turnover of the technology market and foreign direct investment), and basic research (the number of patent applications, the number of papers published, and the proportion of scientific and technological financial expenditure). Each index is evaluated by combining subjective weight and objective weight, as shown in Table 2.

Table 2. Evaluation index system of scientific and technological environment.

\begin{tabular}{|c|c|c|c|c|c|}
\hline \multirow{2}{*}{ Variables } & \multirow{2}{*}{$\begin{array}{l}\text { Indicators Indicating the } \\
\text { Content of Variables }\end{array}$} & \multirow{2}{*}{$\begin{array}{l}\text { Unit of } \\
\text { Indicators }\end{array}$} & \multicolumn{3}{|c|}{ Weights of Indicators } \\
\hline & & & $\begin{array}{l}\text { Subjective } \\
\text { Weight }\end{array}$ & $\begin{array}{l}\text { Objective } \\
\text { Weight }\end{array}$ & $\begin{array}{c}\text { Comprehensive } \\
\text { Weight }\end{array}$ \\
\hline \multirow{3}{*}{ Human resources } & $\begin{array}{l}\text { the number of people in science } \\
\text { and technology }\end{array}$ & $10^{4}$ people & 0.35 & 0.29 & 0.30 \\
\hline & the number of Internet users & $10^{4}$ people & 0.22 & 0.33 & 0.21 \\
\hline & $\begin{array}{l}\text { the full time equivalent of R\&D } \\
\text { personnel }\end{array}$ & persons/year & 0.43 & 0.38 & 0.49 \\
\hline \multirow{2}{*}{$\begin{array}{c}\text { Market } \\
\text { environment }\end{array}$} & $\begin{array}{l}\text { the turnover of technology } \\
\text { market }\end{array}$ & $10^{4}$ yuan & 0.67 & 0.68 & 0.81 \\
\hline & $\begin{array}{l}\text { Foreign Direct Investment } \\
\text { (FDI) }\end{array}$ & $10^{4}$ dollar & 0.33 & 0.32 & 0.19 \\
\hline \multirow{3}{*}{ Basic research } & $\begin{array}{l}\text { the number of three patent } \\
\text { licenses }\end{array}$ & item & 0.41 & 0.59 & 0.67 \\
\hline & $\begin{array}{l}\text { the number of papers } \\
\text { published }\end{array}$ & item & 0.27 & 0.23 & 0.17 \\
\hline & $\begin{array}{l}\text { the proportion of scientific and } \\
\text { technological financial } \\
\text { expenditure }\end{array}$ & $\%$ & 0.32 & 0.17 & 0.15 \\
\hline
\end{tabular}

\subsection{Data Sources}

The research area of this paper selected 30 provinces and municipalities of mainland China, excluding Hong Kong, Macao, and Taiwan, which are different from the statistical caliber of mainland China that will lead to biased results. Tibet is not within the research area of this article due to a lake of data. It should be noted that although province and municipality are two administrative concepts, various statistical indicators of four municipalities (Beijing, Shanghai, Tianjin, and Chongqing) can be compared with those of provinces, and a large number of studies at the provincial level in China do the same.

In Table 1 , the equation for comparative labor productivity is $C L P_{i t}=\frac{G D P_{i t} / \sum G D P_{i t}}{L A B O R_{i t} / \sum L A B O R_{i t}}$, in which $C L P_{\mathrm{it}}, G D P_{\mathrm{it}}$, and $L A B O R_{\mathrm{it}}$ respectively indicate comparative labor productivity, gross national product, and employment figures in area $i$ in year $t$. The fixed assets stock is calculated by the perpetual inventory method. The calculation equation of the industrial adjustment coefficient is $C I A_{\mathrm{it}}=\frac{\sum_{1}^{\mathrm{k}} \mid \text { industry }_{\mathrm{it}}^{\mathrm{k}} \text {-industry } \mathrm{it}_{\mathrm{it}-1}^{\mathrm{k}} \mid}{3}$; that is, the industrial adjustment coefficient $C I A_{\mathrm{it}}$ of area $i$ in year $t$ is the average number of absolute values of the proportion of the industry $k(k=1,2,3)$, industry $\mathrm{it}^{\mathrm{k}}$, in that year and the proportion of industry $k(k=1,2,3)$, industry $y_{\mathrm{it}-1}^{\mathrm{k}}$, in the previous year.

In the scale economy index, the scale of the labor force is selected as the ratio of employed to total population of the region. The scale of education is selected as the number of university students for each $10^{4}$ people. The scale of the economy is selected as the gross domestic product (GDP) density (GDP/land area). The scale of the enterprise is selected as the value of the enterprise assets per capita. 
The traffic scale calculates the concentration of the road network (regional highway length/total national highway length).

The remainder of the original data are mainly from China Statistical Yearbook (2005 to 2018), China Energy Statistics Yearbook (2005 to 2018), China Science and Technology Statistics Yearbook (2005 to 2018), China Environmental Statistical Yearbook (2005 to 2018), and relevant statistical yearbooks of various provinces and cities.

\section{Empirical Analysis}

\subsection{Evaluation of Efficiency in Stage 1}

According to the index value of the DPSIR framework and based on the CRS in the super-SBM model, the results were calculated by Max DEA Ultra software (Beijing Realworld Software Company Ltd, Beijing, China) which is a software specially used to calculate efficiency based on the DEA model. Figure 1 shows the results described by Corel Draw 5, which is a vector graphics tool software produced by Corel Company (Ottawa, Canada). The exact numerical results of efficiency for each region are given in the left half of Table A1 in the Appendix A.

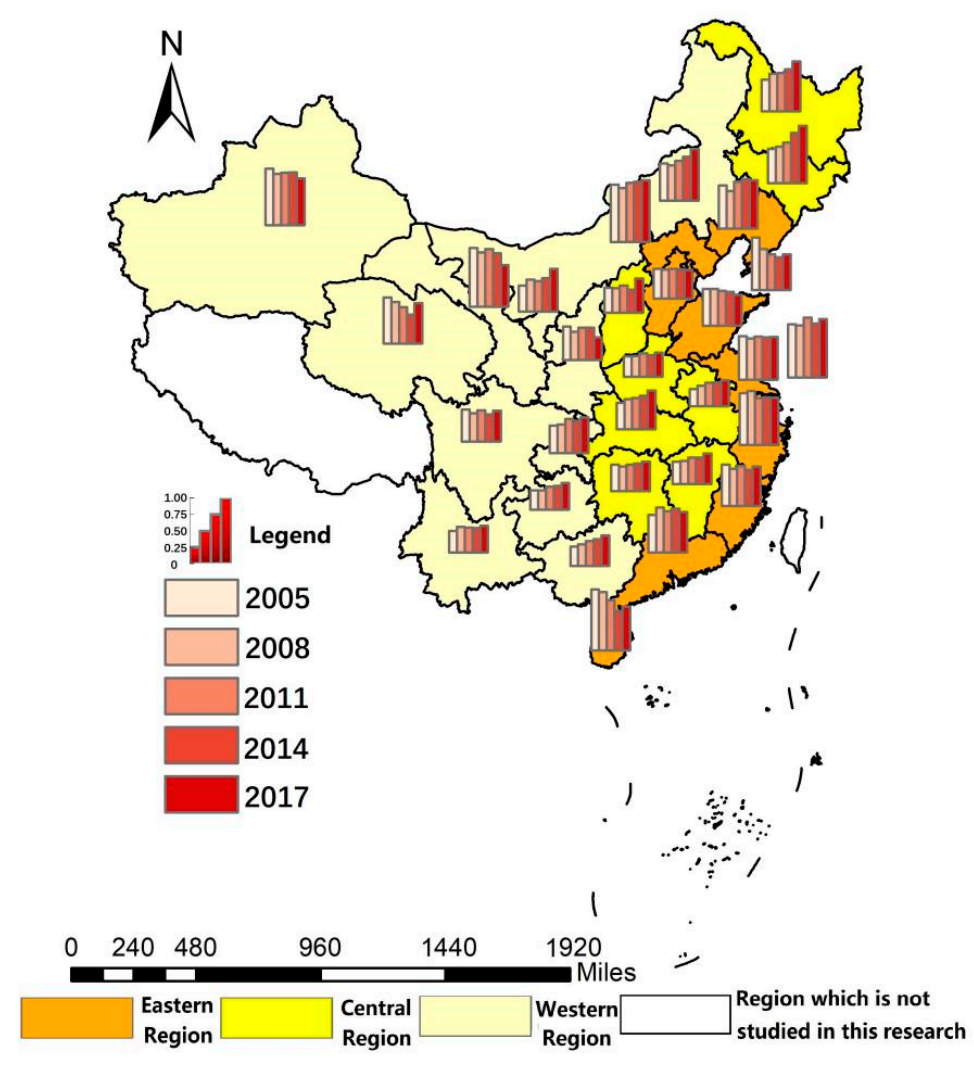

Figure 1. Comprehensive efficiency of stage 1.

From the results of the first stage of comprehensive efficiency, shown in Figure 1, on the time dimension from 2005 to 2008, the efficiency of the 13 provinces and cities increased. The increase in efficiency was mainly concentrated in the Central region, while the efficiency of the 17 provinces and cities, mainly concentrated in the Eastern region, declined by various degrees. This was the fastest-growing period for China's economy, with an average annual GDP growth rate of $12 \%$, but pollution emissions were also the highest. The haze problem is the epitome of China's environmental issues. From 2008 to 2011, the efficiency of 22 provinces and cities showed an upward trend, and eight provinces and cities, concentrated mainly in the Eastern region, decreased. During this period, the national government began to pay attention to environmental protection and issued corresponding 
policies to ensure the improvement of the efficiency of sustainable development in this period. From 2011 to 2014, the efficiency of 16 provinces and cities increased, and 14 provinces and cities declined. The provinces and cities where efficiency rose and fell are evenly distributed in the Eastern, Central, and Western regions. From 2014 to 2017, the efficiency of 21 provinces and cities increased, mainly in the country's the Eastern and Central regions. These two periods represent the adjustment period and the rising period of China's environmental protection policy. On the spatial dimension, the efficiency of the Eastern region showed a slow downward trend but remained at approximately 0.73 . The Eastern region had the highest level of economic development, the most outstanding scientific and technological capacity, and their investment in environmental protection was also greater than in the Central and Western regions. The Central region's efficiency improved significantly, with average efficiency rising from 0.43 to 0.62 . The Western region's efficiency remained stable, with the efficiency value constant in the range of 0.56 to 0.62 . Overall, the comprehensive efficiency of various provinces and cities in China showed a trend of increasing volatility, from 0.65 in 2004 to 0.68 in 2017. With respect to the time dimension, the efficiency of provinces and cities in the measurement period did not fluctuate significantly and remained on an upward trend. The sustainable development efficiency measured in this paper in the time dimension was similar to the green economic efficiency measured by Tao [64], the ecological efficiency measured by Yang [43], the energy and environmental efficiency measured by Wang [46], and the green economic efficiency measured by Su [65], which fluctuate and rise. However, a few studies concluded that China's efficiency has not improved [66] or has even declined [22]. With respect to the spatial dimension, the Eastern region has the most developed economy, which has attracted a substantial population influx leading to urban congestion and ecological destruction causing a decline in efficiency. The result of efficiency decline of sustainable development in Eastern China is consistent with that measured by Shang [67]. The Central region has undertaken science, technology, and management development already in existence in the Eastern region, and its sustainable development efficiency has increased. Due to limitations of the natural environment and increasing intensity of environmental protection policies in the Western region, sustainable development efficiency in this region has remained constant. In the whole measurement period, the evaluation values of ecological efficiency in the Eastern, Central, and Western regions are $0.78,0.52$, and 0.60 . The Eastern region's ecological efficiency is 0.26 higher than that of the Central region. In general, the Eastern region has the highest sustainable development efficiency, which is consistent with the ecological efficiency results measured by Jin [68], Zameer [69], and Yang [43], the green economic efficiency results measured by Tao [64] and Su [65], the carbon dioxide emission efficiency measured by Ding [70], and the energy efficiency measured by Yu [71]. The efficiency of sustainable development in Central China is the lowest, which is consistent with the results of environmental efficiency measured by Song [31], ecological efficiency measured by Yang [72], land use efficiency measured by Yu [73] and Han [74], and cultivated land use efficiency measured by Kuang [75]; although some studies believe that the efficiency in the Western region is the lowest [76].

\subsection{Analysis of Panel Stochastic Frontier Approach Results}

Using the redundant values of the first-stage input variables as the interpreted variables, and using labor force scale, education scale, economic scale, enterprise scale, and traffic scale as explanatory variables, Frontier 4.1, which is a software specially used to complete stochastic frontier analysis by maximum likelihood method, was used to calculate the stochastic frontier approach. The results are as follows.

Table 3 shows that labor force scale, education scale, enterprise scale, and traffic scale have a significant impact on the relaxation variables of the driving force. Among them, labor force scale and traffic scale have positive effects on driving power; that is, labor force scale and traffic scale increase the driving force of sustainable development. The impact of education scale and enterprise scale on driving force is negative; that is, the scale development of education and the scale operation of enterprises reduce the driving force. 
Table 3. Stochastic frontier approach results.

\begin{tabular}{cccc}
\hline the Driving Force & $\begin{array}{c}\text { Relaxation Variable of } \\
\text { the }\end{array}$ & $\begin{array}{c}\text { Relaxation Variable of } \\
\text { the Resource } \\
\text { Consumption Pressure }\end{array}$ & $\begin{array}{c}\text { Relaxation Variable of } \\
\text { the Response }\end{array}$ \\
\hline Constant term & $-0.137^{* * *}$ & $-0.152^{* * *}$ & $-0.269^{* * *}$ \\
Labor force scale & $(-8.226)$ & $(-10.384)$ & $-19.453)$ \\
& $0.162^{* * *}$ & 0.031 & $-0.135^{* *}$ \\
Education scale & $(3.505)$ & $(0.409)$ & $0.025^{* * *}$ \\
Economic scale & $-0.011^{*}$ & $-0.014^{*}$ & $(2.936)$ \\
& $(-1.809)$ & $(-1.675)$ & $-0.032^{* * *}$ \\
Enterprise scale & 0.006 & $0.028^{* * *}$ & $(-2.800)$ \\
& $(0.979)$ & $(2.240)$ & $0.009^{* * *}$ \\
Traffic scale & $-0.003^{* * *}$ & $-0.007^{* * *}$ & $(5.583)$ \\
& $(-2.985)$ & $(-3.965)$ & 0.444 \\
$\sigma^{2}$ & $0.351^{* * *}$ & $0.402^{* *}$ & $(0.991)$ \\
& $(2.726)$ & $(1.990)$ & $0.023^{* * *}$ \\
$\gamma$ & $0.007^{* * *}$ & $0.011^{* * *}$ & $(2.843)$ \\
& $(3.296)$ & $(4.040)$ & $0.933^{* * *}$ \\
& $0.886^{* * *}$ & $0.809^{* * *}$ & $(37.378)$ \\
\hline
\end{tabular}

Note: $* * *, * *, *$ indicate statistical significance at the $1 \%, 5 \%, 10 \%$ level, respectively. The values in parentheses are t statistics.

Education scale, economic scale, enterprise scale, and traffic scale have a significant impact on the resource pressure relaxation variables. Among them, economic scale and traffic scale have positive effects on resource consumption pressure; that is, the large-scale development of economy and transportation will result in the continuous consumption of resources. The impact of education scale and enterprise scale on resource consumption pressure is negative; that is, higher education and enterprise development reduce resource consumption.

Labor force scale, education scale, economic scale, and enterprise scale have a significant impact on the response relaxation variables. Among them, education scale and enterprise scale have positive effects on resource consumption pressure. That is, education level and enterprise development can effectively improve the response level. The impact of labor scale and economic scale on the relaxation variables of response is negative; that is, intensive production reduces the level of response.

According to the influence of various environmental variables on relaxation variables, labor force scale, economic scale, and traffic scale will cause the continuous consumption of resources, which increases the urgency in social demand for sustainable development. Education scale and enterprise scale effectively reflect the level of response.

\subsection{Analysis of Efficiency in Stage 3}

Based on the results in Table 2, adjusting the input and using Max DEA software, the comprehensive efficiency and technical efficiency of sustainable development is calculated, which eliminates the impact of absolute scale. The RSE of sustainable development is the ratio of comprehensive efficiency to technical efficiency, and Figure 2 shows the results. The exact numerical results of efficiency for each region are given in the right half of Table A1 in the Appendix A. 


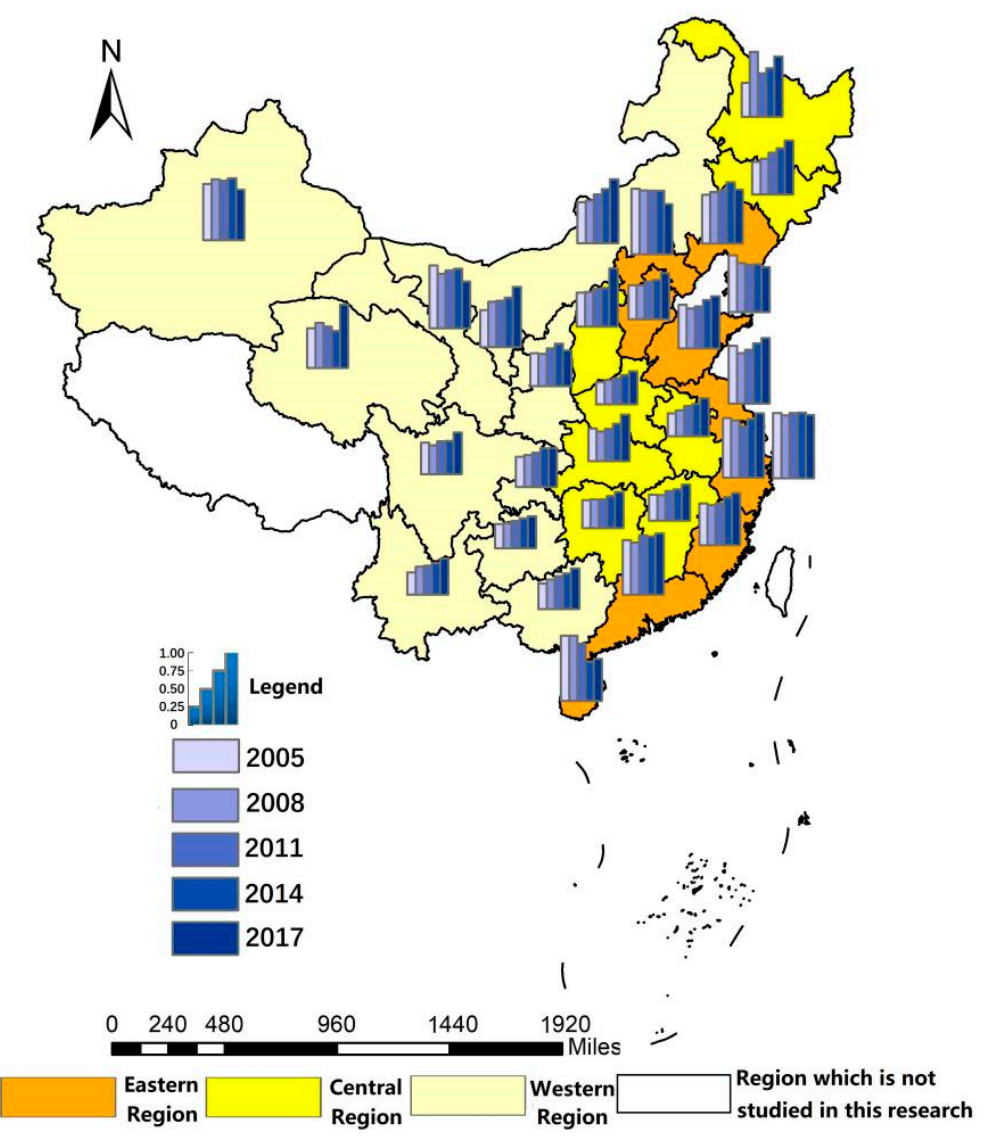

Figure 2. Relative scale efficiency (RSE) of sustainable development.

According to the results of the RSE in Figure 2, for the time dimension, the RSE of 17 provinces and cities showed an upward trend, and the 13 provinces and cities showed a downward trend from 2005 to 2008. The provinces and cities with a decrease in RSE are mainly concentrated in the Eastern and Central regions and, particularly in the Eastern coastal areas, all provinces and cities show a downward trend in addition to the Hebei Province. During this period, with China's accession to the World Trade Organization, the coastal economy was unprecedentedly developed, and as a result, substantial amounts of labor and capital were poured into coastal areas. However, due to a series of problems such as quality of labor and industrial structure, large-scale agglomeration of humans and capital has not led to high efficiency development but has caused low RSE. During the long period from 2008 to 2017, the RSE of most provinces and cities in China increased. The number of provinces and cities with rising RSE in each period is constant at approximately 25, and the average value of RSE has increased from 0.64 to 0.75 . China's sustainable development in this period shows that the relative concentration of capital and manpower has increased the overall level of sustainable development. For the spatial dimension, the RSE of the Eastern region is the highest, the average value is 0.81 , and the second highest RSE is that of the Western region where the average value is 0.63 . RSE is lowest in the Central region with an average value of 0.55 . For the Western region, the RSE of the Northwest region (0.75) is far higher than that of the Southwest region (0.48); thus, the high RSE of the Western region is due to the sustainable development of the Northwest region. Overall, for the measurement period, the RSE of the sustainable development of China's provinces and cities has maintained steady growth after eliminating the environmental factors of the absolute scale, and the growth rate is close to $20 \%$. At the same time, the gap between provinces and cities has shrunk, narrowing the gap from 0.66 in 2005 to 0.51 in 2017. Therefore, we can determine that the external factors lead to the underestimation of sustainable development efficiency in China, which is similar to the energy efficiency measured by Zhao [77] and Wang [78]. 


\section{Threshold Regression Analysis}

After the threshold estimation of the samples, the level of absolute scale (LAS) of Beijing, Tianjin, Shanghai, and Chongqing is far greater than the LAS of the other provinces, with the LAS of the other 26 provinces barely reaching the first threshold level. Considering the obvious gap between the provincial and municipal levels of agglomeration, only the 26 provinces were selected as the research object. The significance of the Hausman test indicates a rejection of the null hypothesis; therefore, a fixed effect model was adopted. Based on this model, the comprehensive efficiency (Figure 1) is interpreted as the explanatory variable, the RSE (Figure 2) is the core explanatory variable, and human resources, the market environment, and basic research (Table 2) are the control variables. The LAS of labor force, education, economics, enterprise, and traffic are the threshold variables. Testing was conducted using Equations (5)-(7) and stata 13.1 software. The bootstrap method was used for sampling, and the bootstrap number was 300 times.

\subsection{Test for Threshold Effect}

The threshold was tested for labor force scale, education scale, economic scale, enterprise scale, and traffic scale, with results located in Table 4. The LAS for labor force and enterprise did not pass the single threshold effect test. The LAS for enterprises did not pass the test of the triple threshold effect, and the remaining threshold variables were tested using the triple threshold test under the $10 \%$ level. Therefore, all the threshold variables are analyzed by the double threshold test because (1) all the threshold variables passed the double threshold test; (2) the significance of the double threshold test of the threshold variables is greater than the single threshold test and the triple threshold test.

Table 4. The value of threshold effect test.

\begin{tabular}{cccccc}
\hline Indicators & $\begin{array}{c}\text { LAS of Labor } \\
\text { Force }\end{array}$ & $\begin{array}{c}\text { LAS of } \\
\text { Education }\end{array}$ & $\begin{array}{c}\text { LAS of } \\
\text { Economic }\end{array}$ & $\begin{array}{c}\text { LAS of } \\
\text { Enterprise }\end{array}$ & LAS of Traffic \\
\hline $\begin{array}{c}\text { Single } \\
\text { threshold test }\end{array}$ & 8.987 & $10.861^{* *}$ & $9.912^{* * *}$ & $7.622^{*}$ & $11.320^{* * *}$ \\
$\begin{array}{c}\text { Double } \\
\text { threshold test }\end{array}$ & 0.113 & 0.020 & 0.000 & 0.067 & 0.000 \\
$\begin{array}{c}\text { Triple } \\
\text { threshold test }\end{array}$ & $0.495^{*}$ & $7.344^{* * *}$ & $10.250^{* * *}$ & $5.315^{* *}$ & $17.647^{* * *}$ \\
\hline
\end{tabular}

Note: The data in the table is the $\mathrm{F}$ statistic corresponding to the threshold test. ${ }^{* * *}, * * *{ }^{*}$ indicate statistical significance at the $1 \%, 5 \%, 10 \%$ level, respectively.

\subsection{Threshold Value Estimation}

The threshold values were estimated for all threshold variables. The results are shown in Table 5 and Figure 3. In this paper, the threshold estimation was combined with the parameter estimation of the model for analysis. The specific analysis is described in the next section.

Table 5. Threshold value estimation.

\begin{tabular}{ccccc}
\hline $\begin{array}{c}\text { Threshold } \\
\text { Variable }\end{array}$ & Threshold Value & $\begin{array}{c}\text { 95\% Confidence } \\
\text { Interval }\end{array}$ & Threshold Value & $\begin{array}{c}\text { 95\% Confidence } \\
\text { Interval }\end{array}$ \\
\hline labor force scale & 0.095 & {$[0.054,0.211]$} & 0.156 & {$[0.149,0.189]$} \\
education scale & 0.929 & {$[0.744,1.852]$} & 2.007 & {$[1.963,2.128]$} \\
economic scale & 0.017 & {$[0.015,0.059]$} & 0.042 & {$[0.033,0.050]$} \\
enterprise scale & 1.985 & {$[1.778,2.187]$} & 7.697 & {$[1.432,8.247]$} \\
traffic scale & 0.040 & {$[0.031,0.053]$} & 0.090 & {$[0.083,0.100]$} \\
\hline
\end{tabular}



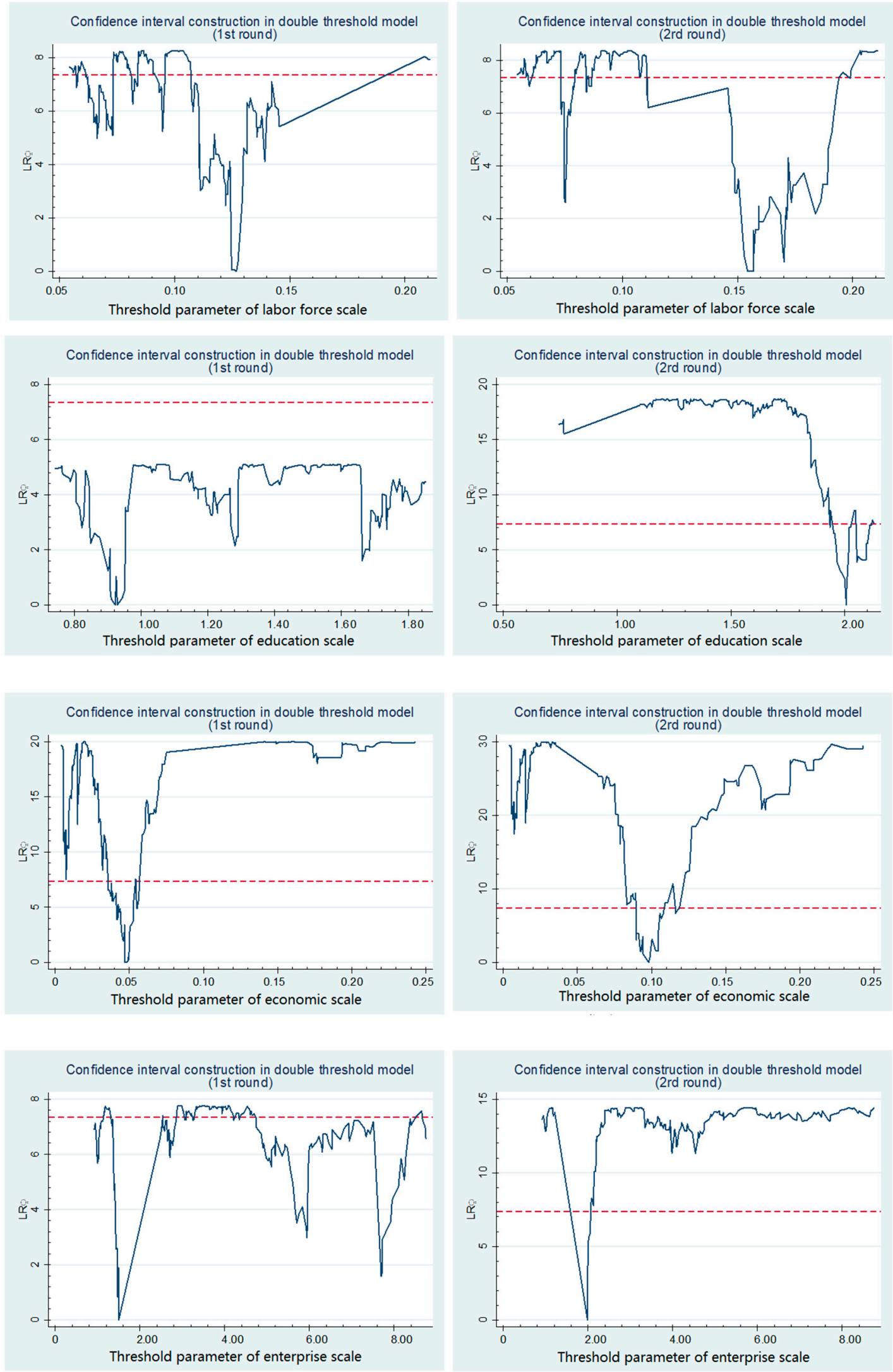

Figure 3. Cont. 

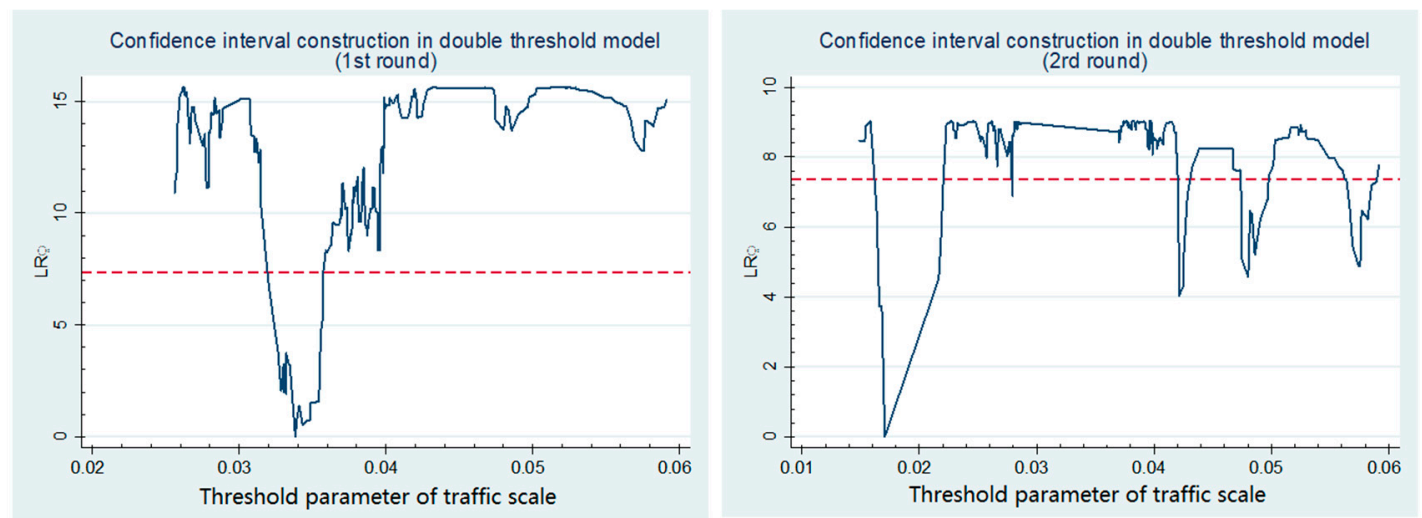

Figure 3. The double threshold of each absolute scale index.

\subsection{Model Parameter Analysis}

Table 6 shows the double threshold parameters of absolute scale indicators.

Table 6. Parameter estimation results of double threshold model.

\begin{tabular}{cccccc}
\hline Variable & $\begin{array}{c}\text { LAS of Labor } \\
\text { Force }\end{array}$ & $\begin{array}{c}\text { LAS of } \\
\text { Education }\end{array}$ & $\begin{array}{c}\text { LAS of } \\
\text { Economic }\end{array}$ & $\begin{array}{c}\text { LAS of } \\
\text { Enterprise }\end{array}$ & LAS of Traffic \\
\hline Human resources & $-0.247^{* * *}$ & $-0.190^{*}$ & $-0.292^{* * *}$ & $-0.216^{* *}$ & $-0.214^{* *}$ \\
& $(-2.79)$ & $(-1.83)$ & $(-3.23)$ & $(-2.36)$ & $(-2.08)$ \\
Market environment & $-0.542^{* * *}$ & $-0.612^{* * *}$ & $-0.419^{* * *}$ & $-0.467^{* * *}$ & $-0.268^{*}$ \\
& $(-3.80)$ & $(-3.70)$ & $(-2.70)$ & $(-3.22)$ & $(-1.94)$ \\
Basic research & $0.137^{*}$ & 0.0633 & -0.000583 & $0.216^{* *}$ & $0.252^{* * *}$ \\
& $(1.68)$ & $(0.72)$ & $(-0.01)$ & $(2.56)$ & $(2.75)$ \\
E·I $\left(\mathrm{Tit}^{<} \delta 1\right)$ & $-0.916^{* * *}$ & $-0.106^{* * *}$ & $-5.779^{*}$ & 0.0135 & $-2.783^{* * *}$ \\
& $(-3.34)$ & $(-3.28)$ & $(-1.73)$ & $(1.43)$ & $(-6.14)$ \\
E.I $\left(\delta 1^{<}\right.$Tit $\left.^{<} \delta 2\right)$ & $-0.731^{* * *}$ & $-0.0600^{* * *}$ & $2.137^{* * *}$ & $-0.00705^{* *}$ & $-1.361^{* * *}$ \\
& $(-4.32)$ & $(-3.52)$ & $(3.24)$ & $(-2.25)$ & $(-6.38)$ \\
E.I(Tit $\left.{ }^{<} \delta 3\right)$ & $-0.383^{* * *}$ & $-0.0277^{*}$ & $0.944^{* *}$ & $-0.0115^{* * *}$ & $-0.526^{* * *}$ \\
& $(-3.31)$ & $(-1.88)$ & $(2.19)$ & $(-5.37)$ & $(-3.93)$ \\
Constant & $0.0403^{*}$ & $0.0740^{* * *}$ & $-0.0691^{* *}$ & $-0.0951^{* * *}$ & -0.014 \\
& $-1.77^{* *}$ & $(2.70)$ & $(-2.03)$ & $(-4.95)$ & $(-0.62)$ \\
\hline
\end{tabular}

Note: ${ }^{* * *}, * * *$ indicate statistical significance at the $1 \%, 5 \%, 10 \%$ level, respectively. The values in parentheses are $\mathrm{t}$ statistics. LAS $=$ level of absolute scale.

(1) Under the LAS for labor force threshold, the RSE of sustainable development has a negative double threshold effect on comprehensive efficiency. The negative effect of sustainable development efficiency of labor scale is consistent with the negative effect of urbanization on green economy efficiency measured by Su [65]. When the LAS of labor force is below 0.095, the elasticity coefficient of RSE on comprehensive efficiency is -0.916 , and the elasticity coefficient is reduced to -731 when crossing this threshold. When the LAS for labor force is above 0.156 , the elasticity coefficient continues to shrink to -0.383 . The negative correlation between the RSE of labor force and the comprehensive efficiency of sustainable development shows that the large-scale labor force utilization in all Chinese provinces has negatively impacted local sustainable development. From the coefficient of different threshold levels, with the constant expansion of the LAS of labor force, the impact of the RSE for labor force on the comprehensive efficiency of sustainable development is gradually decreasing, which indicates that the improvement of the comprehensive efficiency of sustainable development should be the breakthrough point for the restriction of the LAS for labor force.

By observing samples, 26 provinces crossed the first threshold at various times. Jiangsu, Zhejiang, Guangdong, Liaoning, and other Eastern provinces crossed the first threshold earliest, followed by the remaining Eastern provinces and some Central and Western provinces. Distant and isolated Western provinces were the last to cross the first threshold. The time that provinces crossed the first threshold 
was mainly concentrated in 2010 and 2011, with 10 provinces crossing the first threshold during that timeframe. A total of 17 out of 26 provinces crossed the second threshold at various times, and Jiangsu, Zhejiang, and Liaoning again crossed this threshold first. The remaining provinces crossed the second threshold between 2012 and 2017, respectively. The average LAS of labor force in 26 provinces crossed the first threshold in 2010, with seven provinces that crossed the first threshold ahead of the average. The average time for crossing the second threshold was 2015, and nine provinces exceeded the second threshold ahead of the average.

The different threshold stages of the LAS of labor force in the provinces show that the negative impact of RSE on the comprehensive efficiency of sustainable development is declining in Eastern coastal areas, and the LAS mainly affects the comprehensive efficiency of sustainable development. Considering the number of provinces crossing the first and second threshold and the number of provinces crossing the second threshold, the absolute gap between the size of China's labor forces is narrowing, and the relative gap is expanding.

(2) Under the threshold of LAS of education, the RSE of sustainable development has a negative double threshold effect on comprehensive efficiency. When the LAS of education is below 0.929, the elasticity coefficient of RSE to comprehensive efficiency is -0.106 , while the elasticity coefficient decreases to -0.0600 when this threshold is crossed. When the LAS of education is above 0.156 , the elasticity coefficient continues to decrease to -0.0277 . The elasticity coefficients of education under different thresholds are similar to the elasticity coefficients of labor force, but the reasoning is different. Agglomeration of education and educational institutions enhance the overall strength of education. However, the comprehensive efficiency of sustainable development as a long-term investment reflects that current investment in education has a positive impact on long-term development, but it is likely to have a negative impact on the development of society at present. Therefore, under different threshold levels, the coefficient is negative. When the LAS of education reaches a certain level, the relative scale of education highlights its advantages; that is, the negative impact on the comprehensive efficiency of sustainable development during the current period decreases.

In the observed samples, 26 provinces crossed the first threshold at different times. Liaoning, Jilin, Heilongjiang, Jiangsu, Zhejiang, Hubei, and Shaanxi, which have a large number of higher educational institutions, crossed the first threshold first. The Eastern and Central regions crossed the first threshold next, and the provinces that crossed the first threshold last were mainly concentrated in the Western region. Most of the Eastern and Central regions crossed the first threshold before 2006 while most of the Western regions did not cross the first threshold until 2010. Eight of the 26 provinces crossed the second threshold at various times. Jiangsu, Shaanxi, and Hubei crossed the second threshold first while no provinces in the Western region except Shaanxi crossed the second threshold.

The different threshold stages of education in various provinces show that continuous expansion of education scale in provinces with a better education base will greatly reduce the decline in the comprehensive efficiency of sustainable development resulting from educational investment in the current period. A large gap in the LAS of education remains between Western China and the Eastern and Central regions. Considering the number of provinces that crossed the first and second threshold, the absolute disparity and relative gap of China's education scale are constantly expanding.

(3) Under the different thresholds of the LAS of economy, the RSE of economy has different effects on the comprehensive efficiency of sustainable development at different stages. On the whole, the positive impact of China's economic scale on the efficiency of sustainable development is consistent with Jin's [68] results. The difference is that Jin explored the relationship between economic agglomeration and ecological efficiency in different regions in a relevant way. In addition, Wang [79] also found that the economy will have a positive impact on the efficiency of air pollution emissions. When the LAS of economy is below 0.017 , the elastic coefficient of the RSE to the comprehensive efficiency is -5.779 , and the elastic coefficient becomes 2.137 when it crosses the first threshold. When the LAS of economy is above 0.042 , the elasticity coefficient will decrease to 0.944 . In contrast to other absolute scale threshold variables, the RSE of economy has different influence directions and influence coefficients 
under different threshold levels. The reasons for this phenomenon may be that when the LAS of economy is small, society is mainly engaged in low-end production, and the improvement in the RSE of economy is mainly reflected in low-end industries. These industries will incur a flat decline in the comprehensive efficiency for overall sustainable development because of technology and management problems. With technological progress and industrial agglomeration, the development of middleand high-end industries is rapid. Therefore, under this threshold level, improvement in the RSE of economy is mainly embodied in the mid- and high-end industries and will effectively promote the comprehensive efficiency of sustainable development. After the LAS of economy reaches a certain level, continued improvement in the RSE of economy needs more additional related input but will result in diminishing returns on the positive effect on the comprehensive efficiency of sustainable development.

In the observed samples, 22 of 26 provinces crossed the first threshold at various times, and 20 provinces crossed the second threshold at various times. The Central provinces crossed the first threshold in the initial stages of the measurement period and crossed the second threshold in the middle of the measurement period. The majority of the Eastern region crossed the second threshold at the beginning of the measurement period. Most of the provinces in the Western region crossed the first threshold in the middle of the measurement period and crossed the second threshold in the latter stages of the measurement period. Provinces that have not crossed the first threshold include Inner Mongolia, Gansu, Qinghai, and Xinjiang, concentrated in the Western region. Provinces that have not crossed the second threshold include Heilongjiang and Yunnan, which are located in Northeast and Western regions, respectively.

The different threshold stages of the provinces' economic scale indicate that the LAS of economy in most provinces is at a high level, but the threshold stages also show the reality of sustainable development in different regions. Most of the Western regions are at the low end of the industrial chain, and improvement in the RSE of economy has a negative effect on the promotion of the local comprehensive efficiency of sustainable development. Therefore, the Western region should first transform and upgrade the production structure. As a result of the relatively high LAS of economy in the Eastern region, improvement in the RSE of economy has continued to weaken the comprehensive efficiency of sustainable development. The RSE of economy in the Central region has greatly promoted the comprehensive efficiency of local sustainable development before 2007. With implementation of the strategy to boost the Central region, the RSE of economy in the Central region has reached a certain level. Thus, the effect of the RSE of economy on the comprehensive efficiency of the local sustainable development has also been reduced.

(4) Under the threshold of different LASs for enterprise, the RSE of enterprise has different effects on the comprehensive efficiency of sustainable development at different stages. When the LAS of enterprise is below 1.985, the elastic coefficient of the RSE to the comprehensive efficiency is 0.0135 , and the elastic coefficient becomes -0.00705 when it crosses this threshold. When the LAS of enterprise is above 7.697, the elasticity coefficient will continue to expand to -0.0115 . The impact of the RSE of enterprise on the comprehensive efficiency of sustainable development at different threshold levels is the opposite of the impact of the RSE of enterprise because the increasing of the enterprise scale leads to economic development, and there is a time lag. The impact of the RSE of enterprise on the comprehensive efficiency of sustainable development in the present is an indicator of the impact of the RSE of enterprise on the comprehensive efficiency of sustainable development in the future.

In the observed samples, 26 provinces crossed the first threshold at various times. Liaoning, Jiangsu, Zhejiang, and Guangdong, which possess better enterprise bases, crossed the first threshold first. The remaining Eastern and Central regions crossed the first threshold next, and the last provinces to cross the first threshold are mainly concentrated in the Western region. The majority of Eastern and Central regions crossed the first threshold before 2007, while most of the Western regions did not cross the first threshold until 2012. Twelve of 26 provinces entered the second threshold at various times. The provinces that first crossed the second threshold were Jiangsu and Zhejiang followed by the remaining Eastern provinces and some Western region provinces. On aggregate, the LAS of enterprise for the 
provinces crossed the first threshold in 2008, and 11 provinces crossed the first threshold ahead of the average. During the measurement period, the average value failed to exceed the second threshold.

The LAS of enterprise for each province reflects the gap between the east and the west in China. The Eastern region crossed the first threshold before the Central and Western regions, with the Central and Western regions lagging behind the Eastern region by five to seven years. In addition, provinces that crossed the second threshold are mainly concentrated in the Eastern region. The absolute and relative gap between the Eastern region and the Central and Western regions is expanding.

(5) Under the threshold of the LAS of traffic, the RSE of sustainable development has a negative double threshold effect on comprehensive efficiency. The negative impact of China's traffic scale on the efficiency of sustainable development is consistent with the negative impact of passenger and freight volume measured by Chiu [45] on the efficiency of economic development. When the LAS of traffic is below 0.040 , the elastic coefficient of the RSE to the comprehensive efficiency is -2.783 , and the elastic coefficient is reduced to -1.361 when it crosses this threshold. When the LAS of traffic is above 0.090, the elasticity coefficient will continue to shrink to -0.526 . With investment in highway construction, post-investment maintenance cost, and the associated increase in the number of transportation tools, the RSE of traffic and the comprehensive efficiency of sustainable development have a negative correlation. However, with the continuous increase in road network density, accessibility to road networks has improved, and the distance and duration of transportation has been reduced. On the other hand, increased road network density has alleviated congestion, which has effectively limited substantial growth in traffic emissions. Therefore, the negative impact of the RSE of transportation on the comprehensive efficiency of sustainable development decreases when the LAS of traffic reaches a certain level.

In contrast to other scale indicators, the LAS of traffic is selected as the road network density ratio (regional highway length/national highway total length). Therefore, the LAS of traffic in all provinces is maintained in a certain range, with no excessive increase or decline beyond a certain deviation. In the observed samples, 14 of the 26 provinces crossed the first threshold at various times, three provinces eventually regressed to a level that was below the first threshold. Shandong, Henan, Hubei, Hunan, Guangdong, Sichuan, and Yunnan were all higher than the first threshold during the measurement period while Hebei and Anhui were above the first threshold for a long time during the measurement period. Only Yunnan crossed the second threshold during the period 2004 to 2005; other provinces failed to cross the second threshold.

The provinces across the first threshold are mainly concentrated in the Yangtze River Basin (including Jiangsu, Hubei, Hunan, Sichuan, Yunnan, and Anhui) as well as the Yellow River Valley (including Shandong, Henan, and Inner Mongolia), within a prominent area of the road network along the riverline and coastline of China. At the same time, China's road network LAS is shrinking from the perspective of provinces that crossed the second threshold, but it is mainly reflected in the expansion of the road network in the Eastern coastal areas and the relative decrease in the road network in the inland provinces along the river. Considering the different impacts of the RSE on the comprehensive efficiency of sustainable development for different traffic LASs, improvement in the LAS of traffic is beneficial to sustainable development.

\section{Discussion}

Among the five scale indicators, we divide these indicators into three categories when we formulate policies to improve the efficiency of sustainable development; these involve the positive and negative influence coefficients of each indicator on the efficiency of sustainable development under different thresholds: (i) Indicators that need to be further improved, including the scale of labor force, education, and transportation. With the increase of these indicators, the inhibition of sustainable development efficiency will decrease. (ii) Indicators that need to be maintained at a certain level (i.e., economic scale). When the economic scale is maintained at a certain level (between the first threshold and the second threshold), the promotion effect of sustainable development efficiency will be largest. (iii) Indicators 
that need to be controlled (i.e., enterprise scale). When the enterprise scale is larger, its inhibition to the efficiency of sustainable development is stronger. Based on these three categories of indicators, we propose the following policy recommendations. Table A2 in the Appendix A shows which scale indicators should be improved or reduced in different provinces.

(1) Increasing the scale of labor, education, and transportation. In terms of the scale of the labor force, regions should expand their scale on the basis of improving the level of urbanization by actively promoting the citizenization of agricultural transfer population, comprehensively improving urban functions, accelerating the cultivation of small- and medium-sized cities, and characteristic small towns. With increased life expectancy, the central government should gradually raise the legal retirement age or the legal pension retirement age in accordance with the experience of the United States, France, Sweden, and other countries to ensure that the labor force scale does not decline. In terms of education scale, the government should increase support for the cultivation of normal students to improve the number of teachers, increase investment in higher education, and increase the proportion of education expenditure within the government's public expenditure. For those who have already worked, they should be encouraged to participate in continuing education to promote the overall number of years of education for people. In terms of traffic scale, we should continue to invest in the construction of roads in rural areas, ensure the maintenance of roads, and improve the overall transportation network. A three-dimensional traffic system should be established by means of viaducts and underground tunnels in cities.

(2) Keeping the economic scale stable. Although economic development is an important aspect of sustainable development, the empirical results show that the marginal effect of excessive economic scale on the efficiency of sustainable development is small, which is in line with the law of sustainable development. Therefore, for the provinces whose economic scale passed the second threshold, it is not necessary to reduce the economic scale deliberately to promote the efficiency of sustainable development, but they should pay attention to the quality of economic scale. For the provinces (Inner Mongolia, Gansu, Qinghai, and Xinjiang) whose economic scale is below the first threshold, the main way to improve sustainable development efficiency is to continue to expand the economic scale; thus, local governments should focus more on economic development. For provinces (Heilongjiang and Yunnan) whose economic scale is between the first threshold and the second threshold, expanding economic scale can also effectively improve sustainable development efficiency, but we should also pay attention to the quality of economic scale. Local governments can improve their economic scale by setting up green development funds, policies that support ecological protection, environmental governance, and green industry development, and by encouraging financial institutions to increase their support for ecological conservation area projects.

(3) Restraining the enterprise scale appropriately. The scale of enterprises has a restraining effect on the efficiency of sustainable development, and with the increase in enterprise scale, the restraining effect becomes more serious. This is because China's early development mainly focused on the economy, resulting in the growth of many enterprises with non-conforming pollution emissions that endangered the environment. The government should eliminate polluting enterprises through green standards to ensure the survival of green enterprises. Other measures include: (i) optimizing the energy structure and promoting the development of clean energy; (ii) continuing to implement mandatory standards, such as eliminating backward energy consumption and material consumption quotas, pollutant emissions, etc., to force the withdrawal of weak competitive capacity; (iii) issuing a negative list of enterprise investments, and promoting the extension of the industrial chain to the high end; (iv) controlling the new production capacity of steel, chemicals, and other surplus industries.

\section{Conclusions}

Input factors, expected output factors, and non-expected output factors of China's sustainable development were constructed using a DPSIR framework. The sustainable development efficiency of 31 provinces and cities in China was then calculated using a super-SBM-DEA model and the efficiency 
was analyzed through different time periods. The results show an upward trend in sustainable development efficiency in most provinces and municipalities through the time dimension, with the highest increase in efficiency for many provinces and municipalities in the time period between 2008 to 2011. For the spatial dimension, sustainable development efficiency varies greatly among different regions. The Eastern region shows a downward trend, the Central region shows an upward trend, and the Western region is stable.

Next, the three-stage DEA theory to separate the scale of labor force, education, economy, enterprise, and transportation from sustainable development efficiency was used to calculate the scale efficiency of each province and city. The results show that education scale, economic scale, enterprise scale, and transportation scale have significant effects on $\mathrm{P}_{1}$ relaxation variables of resource pressure. Labor scale, education scale, economic scale, and enterprise scale have significant effects on $\mathrm{R}$ relaxation variables. The scale efficiency of the sustainable development of provinces and municipalities, excluding the impact of scale, shows an upward trend, with the highest result in the Eastern region, followed by Western and Central regions.

Finally, using human resources, the market environment, and basic research of scientific and technological innovation as control variables, and by taking the scale of labor force, education, economic, enterprise, and transportation as threshold variables, the impact of sustainable development on relative scale efficiency under different absolute scale thresholds is calculated. The results show that under the threshold of absolute scale of labor force, education, and transportation, the impact of relative scale efficiency of sustainable development on comprehensive efficiency presents a negative two-threshold feature. Under the different threshold of absolute scale of different economies and enterprises, the impact of relative scale efficiency on sustainable development efficiency is different.

Due to regional differences and different stages of development, the attention and evaluation of sustainable development should transfer more to the improvement of efficiency. However, due to the relatively large content of sustainable development, the integration of different aspects of sustainable development (such as driving force, pressure, state, impact, and response) is a more accurate way to measure the efficiency of sustainable development. We should focus on the scale factor and innovation factor when analyzing the influencing factors of sustainable development efficiency. Moreover, we should focus on the interference of another factor when analyzing the influence of one factor, and the idea of a three-stage DEA may be helpful for future research in this area. In addition, the impact of influencing factors on the efficiency of sustainable development may be different under different interference levels, thus, a threshold regression model should be used to explore this difference.

Author Contributions: Methodology, X.W.; writing—original draft preparation, S.W.; writing-review and editing, F.F.; supervision, P.Y.; funding acquisition, J.Z. All authors have read and agreed to the published version of the manuscript.

Funding: This work was supported by the General program of the Chinese National Social Science Foundation (Grant No. 19BGJ033); National Science Foundation of China (NSFC) Funded Projects for Distinguished Young Scholars (Grant No. 41501141 and 41501136); Major program of the Chinese National Social Science Foundation (Grant No. 18ZDA040); China Scholarship Council (CSC) Project (Grant No. 201806270084); China Association for Science and Technology High-end Science and Technology Innovation Think Tank Doctoral Program (Grant No. CXY-ZKQN-2019-052); Guangdong Soft Science Project (Grant No. 2019A101002120); Hubei Soft Science Project (Grant No. 2019ADC130); Shenzhen Planning Fund Project of Philosophy and Social Science (Grant No. SZ2019C003); Chengdu Soft Science Project (Grant No. 2019-RK00-00006-ZF).

Acknowledgments: This article has been corrected by Editage (http://www.editage.cn/) in English. We thank Yan Liu of the School of Earth and Environmental Sciences at the University of Queensland for her help in writing and language. Constructive suggestions and comments on the manuscript from the reviewers and editors are appreciated.

Conflicts of Interest: The authors declare no conflicts of interest. 


\section{Appendix A}

Table A1. Value of comprehensive efficiency and RSE of sustainable development.

\begin{tabular}{|c|c|c|c|c|c|c|c|c|c|c|}
\hline & \multicolumn{5}{|c|}{ Comprehensive Efficiency } & \multicolumn{5}{|c|}{ RSE of Sustainable Development } \\
\hline & 2005 & 2008 & 2011 & 2014 & 2017 & 2005 & 2008 & 2011 & 2014 & 2017 \\
\hline Beijing & 0.98 & 0.93 & 1.01 & 1.03 & 1.06 & 1.00 & 0.98 & 0.97 & 0.97 & 0.77 \\
\hline Tianjin & 0.90 & 0.70 & 0.61 & 0.56 & 0.61 & 0.87 & 0.75 & 0.72 & 0.73 & 0.69 \\
\hline Heibei & 0.51 & 0.49 & 0.51 & 0.50 & 0.49 & 0.52 & 0.52 & 0.58 & 0.61 & 0.71 \\
\hline Shanxi & 0.42 & 0.42 & 0.46 & 0.39 & 0.58 & 0.52 & 0.53 & 0.58 & 0.59 & 0.89 \\
\hline Inner Mongolia & 0.63 & 0.61 & 0.68 & 0.75 & 0.89 & 0.63 & 0.65 & 0.75 & 0.83 & 0.97 \\
\hline Liaoning & 0.73 & 0.64 & 0.80 & 0.85 & 0.83 & 0.74 & 0.79 & 0.82 & 0.94 & 0.82 \\
\hline Jinlin & 0.58 & 0.63 & 0.69 & 0.86 & 0.98 & 0.50 & 0.54 & 0.64 & 0.70 & 0.82 \\
\hline Heilongjiang & 0.54 & 0.64 & 0.66 & 0.72 & 0.85 & 0.52 & 0.99 & 0.66 & 0.74 & 0.92 \\
\hline Shanghai & 0.91 & 0.89 & 1.02 & 0.92 & 1.00 & 1.00 & 0.96 & 1.00 & 1.00 & 0.96 \\
\hline Jiangsu & 0.75 & 0.71 & 0.74 & 0.73 & 0.73 & 0.88 & 0.77 & 0.82 & 0.92 & 1.00 \\
\hline Zhejiang & 0.88 & 0.92 & 0.80 & 0.81 & 0.81 & 0.91 & 0.87 & 0.78 & 0.90 & 0.98 \\
\hline Anhui & 0.29 & 0.35 & 0.40 & 0.41 & 0.44 & 0.35 & 0.39 & 0.46 & 0.49 & 0.58 \\
\hline Fujian & 0.70 & 0.64 & 0.68 & 0.61 & 0.67 & 0.64 & 0.61 & 0.64 & 0.74 & 0.80 \\
\hline Jiangxi & 0.38 & 0.40 & 0.45 & 0.45 & 0.52 & 0.40 & 0.39 & 0.45 & 0.48 & 0.55 \\
\hline Shandnog & 0.63 & 0.63 & 0.60 & 0.58 & 0.53 & 0.67 & 0.61 & 0.64 & 0.74 & 0.80 \\
\hline Henan & 0.35 & 0.36 & 0.40 & 0.37 & 0.41 & 0.34 & 0.37 & 0.39 & 0.45 & 0.50 \\
\hline Hubei & 0.45 & 0.52 & 0.53 & 0.57 & 0.66 & 0.50 & 0.45 & 0.49 & 0.57 & 0.70 \\
\hline Hunan & 0.45 & 0.42 & 0.46 & 0.47 & 0.50 & 0.43 & 0.44 & 0.44 & 0.49 & 0.55 \\
\hline Guangdong & 0.64 & 0.77 & 0.71 & 0.75 & 0.69 & 0.84 & 0.80 & 0.90 & 0.89 & 0.94 \\
\hline Guangxi & 0.33 & 0.37 & 0.42 & 0.45 & 0.52 & 0.39 & 0.45 & 0.50 & 0.55 & 0.62 \\
\hline Hainan & 1.04 & 1.00 & 0.86 & 0.68 & 0.75 & 1.00 & 1.00 & 0.87 & 0.60 & 0.64 \\
\hline Chongqing & 0.47 & 0.49 & 0.58 & 0.55 & 0.61 & 0.46 & 0.49 & 0.53 & 0.59 & 0.59 \\
\hline Sichuan & 0.55 & 0.48 & 0.53 & 0.46 & 0.53 & 0.48 & 0.44 & 0.51 & 0.51 & 0.64 \\
\hline Guizhou & 0.33 & 0.33 & 0.39 & 0.41 & 0.46 & 0.37 & 0.38 & 0.42 & 0.46 & 0.49 \\
\hline Yunnan & 0.37 & 0.44 & 0.43 & 0.42 & 0.46 & 0.34 & 0.43 & 0.45 & 0.48 & 0.55 \\
\hline Shan'xi & 0.57 & 0.48 & 0.55 & 0.55 & 0.39 & 0.50 & 0.49 & 0.58 & 0.65 & 0.55 \\
\hline Gansu & 1.00 & 0.92 & 0.98 & 0.91 & 0.71 & 0.96 & 0.83 & 0.88 & 0.91 & 0.71 \\
\hline Qinghai & 0.79 & 0.71 & 0.62 & 0.49 & 0.69 & 0.61 & 0.69 & 0.64 & 0.57 & 0.97 \\
\hline Ningxia & 0.44 & 0.55 & 0.52 & 0.57 & 0.73 & 0.57 & 0.70 & 0.71 & 0.76 & 0.92 \\
\hline Xinjiang & 0.97 & 0.88 & 0.90 & 0.91 & 0.81 & 0.86 & 0.93 & 0.91 & 0.95 & 0.77 \\
\hline
\end{tabular}

Table A2. The adjustment direction of the scale index of each province.

\begin{tabular}{|c|c|c|c|c|c|c|c|c|c|c|c|}
\hline & $\begin{array}{l}\text { LAS of } \\
\text { Labor } \\
\text { Force }\end{array}$ & $\begin{array}{l}\text { LAS of } \\
\text { Education }\end{array}$ & $\begin{array}{l}\text { LAS of } \\
\text { Economic }\end{array}$ & $\begin{array}{l}\text { LAS of } \\
\text { Enterprise }\end{array}$ & $\begin{array}{l}\text { LAS of } \\
\text { Traffic }\end{array}$ & & $\begin{array}{l}\text { LAS of } \\
\text { Labor } \\
\text { Force }\end{array}$ & $\begin{array}{l}\text { LAS of } \\
\text { Education }\end{array}$ & $\begin{array}{l}\text { LAS of } \\
\text { Economic }\end{array}$ & $\begin{array}{l}\text { LAS of } \\
\text { Enterprise }\end{array}$ & $\begin{array}{l}\text { LAS of } \\
\text { Traffic }\end{array}$ \\
\hline Heibei & $\uparrow \uparrow$ & $\uparrow \uparrow$ & - & $\downarrow$ & $\uparrow \uparrow$ & Hubei & - & - & - & $\downarrow$ & $\uparrow$ \\
\hline Shanxi & $\uparrow$ & - & - & $\downarrow$ & $\uparrow$ & Hunan & $\uparrow$ & $\uparrow$ & - & $\downarrow$ & $\uparrow$ \\
\hline Inner Mongolia & - & $\uparrow$ & $\uparrow$ & $\downarrow$ & $\uparrow$ & Guangdong & - & $\uparrow$ & - & $\downarrow$ & $\uparrow$ \\
\hline Liaoning & - & - & - & $\downarrow$ & $\uparrow$ & Guangxi & $\uparrow$ & $\uparrow$ & - & $\downarrow$ & $\uparrow$ \\
\hline Jinlin & - & - & - & $\downarrow$ & $\uparrow$ & Hainan & - & - & - & $\downarrow$ & $\uparrow$ \\
\hline Heilongiiang & $\uparrow$ & $\uparrow$ & - & $\downarrow$ & $\uparrow$ & Sichuan & - & $\uparrow$ & - & $\downarrow$ & $\uparrow$ \\
\hline Jiangsu & - & - & - & $\downarrow$ & $\uparrow$ & Guizhou & - & $\uparrow$ & - & $\downarrow$ & $\uparrow$ \\
\hline Zhejiang & - & $\uparrow$ & - & $\downarrow$ & $\uparrow$ & Yunnan & - & $\uparrow$ & - & $\downarrow$ & $\uparrow$ \\
\hline Anhui & - & $\uparrow$ & - & $\downarrow$ & $\uparrow$ & Shan'xi & $\uparrow$ & - & - & $\downarrow$ & $\uparrow$ \\
\hline Fujian & - & $\uparrow$ & - & $\downarrow$ & $\uparrow$ & Gansu & - & $\uparrow$ & $\uparrow$ & $\downarrow$ & $\uparrow$ \\
\hline Jiangxi & - & - & - & $\downarrow$ & $\uparrow$ & Qinghai & $\uparrow$ & $\uparrow$ & $\uparrow$ & $\downarrow$ & $\uparrow$ \\
\hline Shandnog & - & $\uparrow$ & - & $\downarrow$ & $\uparrow$ & Ningxia & - & $\uparrow$ & - & $\downarrow$ & $\uparrow$ \\
\hline Henan & $\uparrow$ & $\uparrow$ & - & $\downarrow$ & $\uparrow$ & Xinjiang & $\uparrow$ & $\uparrow$ & $\uparrow$ & $\downarrow$ & $\uparrow$ \\
\hline
\end{tabular}

Note: " $\uparrow$ " indicates that the scale should be expanded, " $\downarrow$ " indicates that the scale should be reduced, and "-" indicates that the original scale should be maintained.

\section{References}

1. United Nations. Agenda 21. 1992. Available online: https://sustainabledevelopment.un.org/content/ documents/Agenda21.pdf (accessed on 16 January 2020).

2. United Nations. Rio Declaration on Environment and Development. 1992. Available online: http: //www.un-documents.net/rio-dec.htm (accessed on 16 January 2020).

3. Peng, S.Z.; Sun, X.Z. Global sustainable development report: Background, progresses and recommendations. China population. Resour. Environ. 2014, 24, 1-5. 
4. Li, L.; Xia, X.H.; Chen, B.; Sun, L. Public participation in achieving sustainable development goals in China: Evidence from the practice of air pollution control. J. Clean. Prod. 2018, 201, 499-506. [CrossRef]

5. Chen, L.; Wang, Y.; Lai, F.; Feng, F. An investment analysis for China's sustainable development based on inverse data envelopment analysis. J. Clean. Prod. 2017, 142, 1638-1649. [CrossRef]

6. Zhan, Y.; Tan, K.H.; Ji, G.; Chung, L.; Chiu, A.S.F. Green and lean sustainable development path in China: Guanxi, practices and performance. Resour. Conserv. Recycl. 2018, 128, 240-249. [CrossRef]

7. Gong, S.S.; Ao, R.J. Foundation of Sustainable Development; Science Press: Beijing, China, 2009.

8. Ren, J.L. Introduction to Regional Sustainable Development; Science Press: Beijing, China, 2014.

9. Tan, F.; Lu, Z. Assessing regional sustainable development through an integration of nonlinear principal component analysis and Gram Schmidt orthogonalization. Ecol. Ind. 2016, 63, 71-81. [CrossRef]

10. Orenstein, D.E.; Pinsley, D.S. A Comparative Framework for Assessing Sustainability Initiatives at the Regional Scale. World Dev. 2017, 98, 245-256. [CrossRef]

11. Wan, L.; Zhang, Y.; Qi, S.; Li, H.; Chen, X.; Zang, S. A study of regional sustainable development based on GIS/RS and SD model — Case of Hadaqi industrial corridor. J. Clean. Prod. 2017, 142, 654-662. [CrossRef]

12. Carrillo, M.; Jorge, J. Multidimensional Analysis of Regional Tourism Sustainability in Spain. Ecol. Econ. 2017, 140, 89-98. [CrossRef]

13. Arbolino, R.; Boffardi, R.; Lanuzza, F.; Ioppolo, G. Monitoring and evaluation of regional industrial sustainability: Evidence from Italian regions. Land Use Policy 2018, 75, 420-428. [CrossRef]

14. Chelan, M.M.; Alijanpour, A.; Barani, H.; Motamedi, J.; Azadid, H.; Passel, S.V. Economic sustainability assessment in semi-steppe rangelands. Sci. Total Environ. 2018, 637-638, 112-119. [CrossRef]

15. Su, Y.; An, X. Application of threshold regression analysis to study the impact of regional technological innovation level on sustainable development. Renew. Sustain. Energy Rev. 2018, 89, 27-32.

16. Zhang, J.; Zhang, L.; Wang, S.; Fan, F. Study on regional sustainable development efficiency measurement and influencing factors: Based on DPSIR-DEA Model. China Popul. Resour. Environ. 2017, 27, 1-9.

17. Tang, H.L.; Pan, F.Q.; Luo, S.L.; Liu, T.; Zhang, L.X. Review and prospect of studies on subway operation efficiency. Technol. Econ. Areas Commun. 2017, 19, 24-28.

18. Wanke, P.; Chen, Z.; Zheng, X.; Antunes, J. Sustainability efficiency and carbon inequality of the Chinese transportation system: A Robust Bayesian Stochastic Frontier Analysis. J. Environ. Manag. 2020, 260, 110163. [CrossRef] [PubMed]

19. Yan, Y.; Wang, C.; Quan, Y.; Wu, G.; Zhao, J. Urban sustainable development efficiency towards the balance between nature and human well-being: Connotation, measurement, and assessment. J. Clean. Prod. 2018, 178, 67-75. [CrossRef]

20. George, E.H.; Nickolaos, G. Economic efficiency and growth in the EU enlargement. J. Policy Model. 2009, 31, 847-862.

21. Deliktas, E.; Günal, G.G. Economic growth and input use efficiency in low, upper -middle and high incomed countries (1991-2011): A data envelopment analysis. Procedia Econ. Financ. 2016, 38, 308-317. [CrossRef]

22. Yang, T.; Chen, W.; Zhou, K.; Ren, M. Regional energy efficiency evaluation in China: A super efficiency slack-based measure model with undesirable outputs. J. Clean. Prod. 2018, 198, 859-866. [CrossRef]

23. Sun, J.; Harimaya, K.; Yamori, M. Regional economic development, strategic investors, and efficiency of Chinese city commercial banks. J. Bank. Financ. 2013, 37, 1602-1611. [CrossRef]

24. Wang, S.; Jia, M.; Zhou, Y.; Fan, F. Impacts of changing urban form on ecological efficiency in China: A comparison between urban agglomerations and administrative areas. J. Environ. Plan. Manag. 2019. Available online: https://www.tandfonline.com/doi/abs/10.1080/09640568.2019.1689932 (accessed on 1 March 2020). [CrossRef]

25. Gong, X.; Wu, X.; Luo, M. Company Performance and Environmental Efficiency: A Case Study for Shipping Enterprises. Transport Policy. Available online: https://ac.els-cdn.com/S0967070X17305966/1s2.0-S0967070X17305966-main.pdf?_tid=9bbdff94--5edc-4b61-bb96--8d6977ccf186\&acdnat=1535606696_ 2bc78891714d1ce019ade60e9718bc65 (accessed on 4 May 2018).

26. Wang, S.; Zhang, J.; Fan, F.; Lu, F.; Yang, L. The symbiosis of scientific and technological innovation efficiency and economic efficiency in China - an analysis based on data envelopment analysis and logistic model. Technol. Anal. Strateg. Manag. 2019, 31, 67-80. [CrossRef]

27. Fan, F.; Lian, H.; Wang, S. Can regional collaborative innovation improve innovation efficiency? An empirical study of Chinese cities. Growth Chang. 2020, 51, 440-463. [CrossRef] 
28. Madaleno, M.; Moutinho, V.; Robaina, M. Economic and environmental assessment: EU cross-country efficiency ranking analysis. Energy Procedia 2016, 106, 134-154. [CrossRef]

29. Moutinho, V.; Madaleno, M.; Robaina, M. The economic and environmental efficiency assessment in EU cross-country: Evidence from DEA and quantile regression approach. Ecol. Ind. 2017, 78, 85-97. [CrossRef]

30. Xing, Z.; Wang, J.; Zhang, J. Expansion of environmental impact assessment for eco-efficiency evaluation of China's economic sectors: An economic input-output based frontier approach. Sci. Total Environ. 2018, 635, 284-293. [CrossRef] [PubMed]

31. Song, M.; Peng, J.; Wang, J.; Zhao, J. Environmental efficiency and economic growth of China: A Ray slack-based model analysis. Eur. J. Oper. Res. 2018, 269, 51-63. [CrossRef]

32. Deilmann, C.; Lehmann, I.; DReißmann, D.; Hennersdorf, J. Data envelopment analysis of cities - Investigation of the ecological and economic efficiency of cities using a benchmarking concept from production management. Ecol. Ind. 2016, 67, 798-806. [CrossRef]

33. Suzuki, S.; Nijkamp, P. An evaluation of energy-environment-economic efficiency for EU, APEC and ASEAN countries: Design of a target-oriented DFM model with fixed factors in data envelopment analysis. Energy Policy 2016, 88, 100-112. [CrossRef]

34. Sun, C.; Wang, S.; Zou, W.; Wang, Z. Estimating the efficiency of complex marine systems in China's coastal regions using a network Data Envelope Analysis model. Ocean Coast. Manag. 2017, 139, 77-91. [CrossRef]

35. Huang, J.; Xia, J.; Yu, Y.; Zhang, N. Composite eco-efficiency indicators for China based on data envelopment analysis. Ecol. Ind. 2018, 85, 674-697. [CrossRef]

36. Ping, X.B.; Chen, L.R. Correctly applying the growth pole theory to guide the economic development of backward areas in China. Econ. Res. Guide 2007, 10, 158-159.

37. Tzeremes, N.G. The effect of human capital on countries' economic efficiency. Econ. Lett. 2014, 124, $127-131$. [CrossRef]

38. Aparicio, J.; Pastor, J.T.; Zofio, J.L. How to properly decompose economic efficiency using technical and allocative criteria with non-homothetic DEA technologies. Eur. J. Oper. Res. 2015, 240, 882-891. [CrossRef]

39. Wang, Z.; He, W.; Chen, K. The integrated efficiency of economic development and $\mathrm{CO}_{2}$ emissions among Asia Pacific Economic Cooperation members. J. Clean. Prod. 2016, 131, 765-772. [CrossRef]

40. Sebastián, L.; Laura, C.I. Dominance network analysis of economic efficiency. Expert Syst. Appl. 2017, 82, 53-66.

41. Zorzo, L.S.; Diehl, C.A.; Venturini, J.C.; Zambon, E.P. The relationship between the focus on innovation and economic efficiency: A study on Brazilian electric power distribution companies. RAI Rev. Adm. Inov. 2017, 14, 235-249. [CrossRef]

42. Habyarimana, J.B.; Opoku, E.E.O. Technological Progress, Worker Efficiency, and Growth in Africa: Does China's Economy Matter? China Economic Review. Available online: https: //ac.els-cdn.com/S1043951X18300944/1-s2.0-S1043951X18300944-main.pdf?_tid=a147a2d2--90e6--4997-8091--5bc8110cff44\&acdnat=1535274226_79bcbd9045e8f5c2afa36cdbfcc9cfb0 (accessed on 14 July 2018).

43. Yang, L.; Zhang, X. Assessing regional eco-efficiency from the perspective of resource, environmental and economic performance in China: A bootstrapping approach in global data envelopment analysis. J. Clean. Prod. 2018, 173, 100-111. [CrossRef]

44. Urbaniec, K.; Mikulčić, H.; Wang, Y.; Duić, N. System integration is a necessity for sustainable development. J. Clean. Prod. 2018, 195, 122-132. [CrossRef]

45. Chiu, Y.; Huang, C.; Ma, C. Assessment of China transit and economic efficiencies in a modified value-chains DEA model. Eur. J. Oper. Res. 2011, 209, 95-103. [CrossRef]

46. Wang, Z.; Feng, C. A performance evaluation of the energy, environmental, and economic efficiency and productivity in China: An application of global data envelopment analysis. Appl. Energy 2015, 147, 617-626. [CrossRef]

47. Huang, Z.; He, C.; Zhu, S. Do China's economic development zones improve land use efficiency? The effects of selection, factor accumulation and agglomeration. Landsc. Urban Plan. 2017, 162, 145-156. [CrossRef]

48. Huang, Y.; Li, L.; Yu, Y. Do urban agglomerations outperform non-agglomerations? A new perspective on exploring the eco-efficiency of Yangtze River Economic Belt in China. J. Clean. Prod. 2018, 202, 1056-1067. [CrossRef]

49. Han, B.; Ouyang, Z.; Wang, W. The relationship between regional industrial organizing levels and ecological economic efficiency. J. Clean. Prod. 2018, 171, 857-866. [CrossRef] 
50. Deilmann, C.; Hennersdorf, J.; Lehmann, I.; Reißmann, D. Data envelopment analysis of urban efficiency Interpretative methods to make DEA a heuristic tool. Ecol. Ind. 2018, 84, 607-618. [CrossRef]

51. Bian, Y.; Hu, M.; Wang, Y.; Xu, H. Energy efficiency analysis of the economic system in China during 1986-2012: A parallel slacks-based measure approach. Renew. Sustain. Energy Rev. 2016, 55, 990-998. [CrossRef]

52. Rajbhandari, A.; Zhang, F. Does energy efficiency promote economic growth? Evidence from a multicountry and multisectoral panel dataset. Energy Econ. 2018, 69, 128-139. [CrossRef]

53. Vaninsky, A. Energy-environmental efficiency and optimal restructuring of the global economy. Energy 2018, 153, 338-348. [CrossRef]

54. Charnes, A.; Cooper, W.W.; Rhodes, E. Measuring the Efficiency of Decision Marking Units. Eur.J. Oper. Res. 1978, 2, 429-444. [CrossRef]

55. Wang, S.; Sun, C.; Li, X.; Zou, W. Sustainable development in China's coastal area: Based on the driver-pressure-state-welfare-response framework and the data envelopment analysis model. Sustainability 2016, 8, 958. [CrossRef]

56. Zhang, J.; Chen, P.; Wang, S.; Fan, F. Study on spatial differentiation of the prefecture and above cities in the Yangtze River Economic Zone based on "lake effect". China Popul. Resour. Environ. 2018, 28, 65-75.

57. Zhao, G.; $\mathrm{Wu}, \mathrm{H}$. The empirical analysis of slack-based-measure efficiency in China's insurance industry—based on modified three-stage data envelopment analysis. J. Guangdong Univ. Financ. 2010, 6, 72-84.

58. Tone, K. Dealing with Undesirable Outputs in DEA: A Slacks Based Measure (SBM) Approach. GRIPS Research Report Series I. 2003. Available online: https://www.researchgate.net/publication/284047010_Dealing with_undesirable_outputs_in_DEA_a_Slacks-Based_Measure_SBM_approach (accessed on 1 March 2020).

59. Fukuyama, H.; Weber, W. A directional slacks-based measure of technial inefficiency. Soc. Econ. Plan. Sci. 2009, 43, 274-287. [CrossRef]

60. Fan, D.; Wang, W. Analysis of total factor energy efficiency and potential of the energy-saving and emission-abating in regional of China-Based on SBM model of undesired output. Math. Pract. Theory 2013, $43,12-21$.

61. Tone, K. A slack-based measure of super-efficiency in data envelopment analysis. Eur. J. Oper. Res. 2002, 143, 32-41. [CrossRef]

62. Fried, H.O.; Lovell, C.A.K.; Schmidt, S.S.; Yaisawarng, S. Accounting for environmental effects and statistical noise in data envelopment analysis. J. Product. Anal. 2002, 17, 121-136. [CrossRef]

63. Liu, N.; Fan, F. Threshold effect of international technology spillovers on China's regional economic growth. Technol. Anal. Strateg. Manag. 2020. Available online: https://www.tandfonline.com/doi/abs/10.1080/ 09537325.2020.1729977 (accessed on 1 March 2020). [CrossRef]

64. Tao, X.; Wang, P.; Zhu, B. Provincial green economic efficiency of China: A non-separable input-output SBM approach. Appl. Energy 2016, 171, 58-66. [CrossRef]

65. Su, S.; Zhang, F. Modeling the role of environmental regulations in regional green economy efficiency of China: Empirical evidence from super efficiency DEA-Tobit model. J. Environ. Manag. 2020, 261, 110227.

66. Piao, S.; Li, J.; Ting, C. Assessing regional environmental efficiency in China with distinguishing weak and strong disposability of undesirable outputs. J. Clean. Prod. 2019, 227, 748-759. [CrossRef]

67. Shang, Y.; Liu, H.; Lv, Y. Total factor energy efficiency in regions of China: An empirical analysis on SBM-DEA model with undesired generation. J. King Saud Univ. Sci. 2020, in press. Available online: https: //www.sciencedirect.com/science/article/pii/S1018364720300355 (accessed on 16 January 2020). [CrossRef]

68. Jin, X.; Li, X.; Feng, Z.; Wu, J.; Wu, K. Linking ecological efficiency and the economic agglomeration of China based on the ecological footprint and nighttime light data. Ecol. Ind. 2020, 111, 106035. [CrossRef]

69. Zameer, H.; Yasmeen, H.; Wang, R.; Tao, J.; Malik, M.N. An empirical investigation of the coordinated development of natural resources, financial development and ecological efficiency in China. Resour. Policy 2020, 65, 101580. [CrossRef]

70. Ding, L.; Yang, Y.; Wang, W.; Calin, A.C. Regional carbon emission efficiency and its dynamic evolution in China: A novel cross efficiency-malmquist productivity index. J. Clean. Prod. 2019, 241, 118260. [CrossRef]

71. Yu, J.; Zhou, K.; Yang, S. Regional heterogeneity of China's energy efficiency in "new normal": A meta-frontier Super-SBM analysis. Energy Policy 2019, 134, 110941. [CrossRef] 
72. Yang, L.; Ma, C.; Yang, Y.; Zhang, E.; Lv, H. Estimating the regional eco-efficiency in China based on bootstrapping by-production technologies. J. Clean. Prod. 2020, 243, 118550. [CrossRef]

73. Yu, J.; Zhou, K.; Yang, S. Land use efficiency and influencing factors of urban agglomerations in China. Land Use Policy 2019, 88, 104143. [CrossRef]

74. Han, H.; Zhang, X. Static and dynamic cultivated land use efficiency in China: A minimum distance to strong efficient frontier approach. J. Clean. Prod. 2020, 246, 119002. [CrossRef]

75. Kuang, B.; Lu, X.; Zhou, M.; Chen, D. Provincial cultivated land use efficiency in China: Empirical analysis based on the SBM-DEA model with carbon emissions considered. Technol. Forecast. Soc. Chang. 2020, 151, 119874. [CrossRef]

76. Zhu, L.; Wang, Y.; Shang, P.; Qi, L.; Yang, G.; Wang, Y. Improvement path, the improvement potential and the dynamic evolution of regional energy efficiency in China: Based on an improved nonradial multidirectional efficiency analysis. Energy Policy 2019, 133, 110883. [CrossRef]

77. Zhao, H.; Guo, S.; Zhao, H. Provincial energy efficiency of China quantified by three-stage data envelopment analysis. Energy 2019, 166, 96-107. [CrossRef]

78. Wang, Z.; Sun, Y.; Yuan, Z.; Wang, B. Does energy efficiency have a spatial spill-over effect in China? Evidence from provincial-level data. J. Clean. Prod. 2019, 241, 118258.

79. Wang, K.; Miao, Z.; Zhao, M.; Miao, C.; Wang, Q. China's provincial total-factor air pollution emission efficiency evaluation, dynamic evolution and influencing factors. Ecol. Ind. 2019, 107, 105578. [CrossRef]

(C) 2020 by the authors. Licensee MDPI, Basel, Switzerland. This article is an open access article distributed under the terms and conditions of the Creative Commons Attribution (CC BY) license (http://creativecommons.org/licenses/by/4.0/). 